\title{
Does Renewable Energy Generation Decrease the Volatility of Electricity Prices? An Analysis of Denmark and Germany
}

\author{
Tuomas Rintamäki \\ Systems Analysis Laboratory, Department of Mathematics and Systems Analysis, School of Science, Aalto \\ University, Finland \\ Afzal S. Siddiqui* \\ Department of Statistical Science, University College London, UK and Department of Computer and \\ Systems Sciences, Stockholm University, Sweden \\ Ahti Salo \\ Systems Analysis Laboratory, Department of Mathematics and Systems Analysis, School of Science, Aalto \\ University, Finland
}

\begin{abstract}
Although variable renewable energy (VRE) technologies with zero marginal costs decrease electricity prices, the literature is inconclusive about how the resulting shift in the supply curves impacts price volatility. Because the flexibility to respond to high peak and low offpeak prices is crucial for demand-response applications and may compensate for the losses of conventional generators caused by lower average prices, there is a need to understand how the penetration of VRE affects volatility. In this paper, we build distributed lag models with Danish and German data to estimate the impact of VRE generation on electricity price volatility. We find that in Denmark wind power decreases the daily volatility of prices by flattening the hourly price profile, but in Germany it increases the volatility because it has a stronger impact on off-peak prices. Our analysis suggests that access to flexible generation capacity and wind power generation patterns contribute to these differing impacts. Meanwhile, solar power decreases price volatility in Germany. By contrast, the weekly volatility of prices increases in both areas due to the intermittency of VRE. Thus, policy measures for facilitating the integration of VRE should be tailored to such region-specific patterns.

Keywords: Electricity price volatility, time-series model, wind power, solar power, Nord Pool, EEX
\end{abstract}

\footnotetext{
${ }^{*}$ Corresponding author

Email addresses: tuomas.rintamaki@aalto.fi (Tuomas Rintamäki), afzal.siddiqui@ucl.ac.uk (Afzal S. Siddiqui*), ahti.salo@aalto.fi (Ahti Salo)
} 


\section{Introduction}

The adoption of variable renewable energy (VRE) technologies is having profound consequences for the electric power industry. For example, buttressed by subsidies and priority grid access, solar and wind power generation in Germany comprised 25\% of national electricity output in 2013 and facilitated a 30\% reduction in $\mathrm{CO}_{2}$ emissions relative to 1990 levels (von Hirschhausen, 2014). Likewise, neighbouring Denmark has adopted VRE-friendly policies enabling it to meet nearly $40 \%$ of its electricity needs through wind (Energinet.dk, 2015). However, similar shares of VRE generation in different electricity markets have resulted in contrasting effects on daily price volatility, which will affect the profitability of conventional power plants. Indeed, via a supply-function equilibrium model, Green and Vasilakos (2010) demonstrate that the incorporation of intermittent renewable resources can increase price volatility in the British electricity industry. Such a change in market dynamics will likely lead to an optimal generation mix using more gas-fired plants in the long run (Green and Vasilakos, 2011). Hence, understanding how VRE generation affects price volatility and uncovering the drivers of these effects is important for both power companies and regulators dealing with a transition to a more sustainable energy system.

While fundamental models are often used to examine policy implications, e.g., in terms of transmission expansion to accommodate increased VRE capacity (Egerer et al., 2013), such models need to be sufficiently detailed to capture the subtle changes that we seek to detect here. In particular, building and calibrating large-scale fundamental models with interconnected regions is often confounded by the complexities of deregulated electricity industries and the associated data requirements at the plant level, for example. By contrast, since the electricity industry is one of the few infrastructure industries with liquid markets and publicly available data on prices as well as cross-border transmission flows, we exploit this feature in taking an empirical approach to understand the effects of VRE generation on price volatility in Danish and German electricity markets.

Our methodology is largely based on Mauritzen (2010) who represents the volatility of prices via a seasonal autoregressive moving average (SARMA) model in which wind power production is an exogenous variable. This methodology yields results that are straightforward to interpret and makes it possible to develop forecasts for electricity price volatility based on the data from previous days and information on regular consumption patterns. His conclusion is that Danish wind power decreases the daily volatility of the area prices in Denmark. On the contrary, Ketterer (2014) uses a generalised autoregressive conditional heteroscedasticity $(\mathrm{GARCH})$ model and finds that German wind power increases the daily volatility of German

electricity prices. Explaining these results using data from the two markets and distilling their implications for electricity markets in general is the objective of this paper. 
We proceed by first confirming the differing impacts of wind power on price volatility in these two markets and then explaining them by dividing the dataset into peak and off-peak hours with separate regressions for each subset of hours. This allows us to analyse changes in volatility by relating them to supply-curve elasticities and to the patterns of wind and solar power production as well as cross-border exchanges. Partitioning the dataset reveals that wind power output decreases daily price volatility in Denmark because wind speeds are roughly evenly distributed throughout the day. Relative to its average electricity demand, Denmark has high transmission capacity to the Nordic countries with large hydropower reservoirs, which may also explain Denmark's reduction in daily price volatility as both peak and off-peak hour prices are estimated to decrease nearly equally due to wind power generation. In Germany, however, there is an increase in price volatility because of greater wind power output during off-peak hours. Moreover, Germany's cross-border transmission lines are smaller relative to its average electricity demand, and it has limited access to flexible hydro generation. As a consequence, prices diverge as the price-decreasing impact of wind power is amplified during off-peak hours. Over a weekly time horizon, the level and the standard deviation of total VRE generation are found to increase the weekly volatility of electricity prices in both countries.

For producers and consumers alike, our empirical analysis not only corroborates earlier findings but also explains them by proposing plausible drivers. The implication of our results is that the allocation of generation and demand is becoming more important as average power prices decrease, but the achievable profit on different days varies significantly. To prevent intermittent renewable generation from threatening the stability of the power system, investments in flexible generation, extensions to the transmission network, integration of adjacent markets, and demand response will be required in the future. Moreover, additional trading opportunities by both producers and large consumers in intraday and balancing markets may be desirable (Mauritzen, 2015).

This paper is organised as follows. In Section 2, we review the literature on the impacts of VRE on Danish and German electricity markets, in particular. In Section 3, we present our model and analyse the time-series data. Section 4 presents the results for the effects of VRE generation on daily and weekly volatility. Finally, in Section 5, we provide conclusions

and discuss directions for future research. Details on model selection and robustness checks are provided in the Appendix.

\section{Literature Review}

The adoption of wind and solar generation technologies worldwide has necessitated a need to assess both the availability of resources (Yip et al., 2016) and their impact on electricity 
markets (González-Aparicio and Zucker, 2015). Many studies have investigated the effect of wind power production on price levels and reached the common conclusion that wind power decreases prices. For example, Jónsson et al. (2010) employ the same hourly Danish wind power forecast data that are used by market players to place their bids. They build a nonparametric regression model to study price levels as well as the distribution of the prices at different wind power levels. Their conclusion is that higher wind power penetration in the day-ahead market decreases Danish prices and volatility substantially.

In Germany, price volatility has been studied by incorporating various market-related measures as exogenous variables (Kalantzis and Milonas, 2013 and Frömmel et al., 2014). Only recently have there been studies on the direct effects of growing capacity of wind and solar power on electricity prices. Ketterer (2014) finds that higher wind power production leads to higher daily volatility. Moreover, she notes that regardless of the regulatory change in 2010, which forced the German transmission system operators to publish day-ahead forecasts for VRE generation in their area, the volatility-increasing effect has prevailed. Because the price-decreasing impact of solar power is stable during peak hours (Paraschiv et al., 2014), it is likely that solar power decreases price volatility.

Besides patterns of solar and wind power production, transmission flows also affect the volatility of electricity prices as suggested by the complementarity model by Morales et al. (2011), who use wind power scenarios as inputs. By adopting the same time-series framework as in Mauritzen (2010), Mauritzen (2013) investigates how wind power affects the cross-border transmission of electricity between Denmark and Norway. His conclusion is that when more (less) wind power is produced in Denmark, exports to (imports from) Norway are higher while Norwegian hydropower plants produce less (more). Zugno et al. (2013) find a similar pattern between Germany and hydro-dominant Austria and Switzerland, but these transmission lines are closer to congestion. Moreover, the flow to the Nordic countries from Germany is low, and the flow to its neighbouring countries with inflexible generation such as France does not respond much to changes in wind power.

Building on assumptions about extended cross-border transmission and VRE capacity in 2030, Jaehnert et al. (2013) find that price spikes and dips become more frequent in the European power market. Due to the large price difference between the Nordic and German markets, also additional investments in transmission capacity become optimal. In similar scenarios, Farahmand et al. (2012) find that the integration of Nordic and German balancing markets via simultaneous dispatching can reduce balancing costs considerably because VRE generation forecast errors with opposite signs can be netted.

In addition to explaining the results of Ketterer (2014) and Mauritzen (2010), our approach of dividing the data into off-peak and peak hours contributes to the literature on 
estimating the impact of renewable generation on electricity price levels (see Würzburg et al. (2013), Mulder and Scholtens (2013), Paraschiv et al. (2014), and Gelabert et al. (2011), for example) by providing insights on how the price-decreasing impact is distributed during the day. To this end, Barthelmie et al. (1996) and Holttinen (2005) suggest that Danish wind power peaks in the afternoon and the effect is more pronounced in summers. On the other hand, He et al. (2012) and Huber et al. (2014) show that German wind power tends to peak at night and also in summer afternoons.

\section{Methodology and Data}

\subsection{Model}

To estimate the effect of exogenous variables such as wind and solar power on a dependent variable of interest such as electricity price volatility, we use the seasonally adjusted autoregressive moving average $(\operatorname{SARMA}(\mathrm{p}, \mathrm{q})(\mathrm{P}, \mathrm{Q})[\mathrm{s}])$ model (Shumway and Stoffer, 2011):

$$
v_{t}=\alpha_{0}+\sum_{i=1}^{p} \alpha_{i} v_{t-i}+\sum_{i=1}^{q} \beta_{i} \epsilon_{t-i}+\sum_{i=1}^{P} \alpha_{i \cdot s} v_{t-i \cdot s}+\sum_{i=1}^{Q} \beta_{i \cdot s} \epsilon_{t-i \cdot s}+\epsilon_{t}+\gamma^{\top} x_{t}
$$

where $v_{t}$ is the dependent variable during time period $t$ and $x_{t}$ a vector of exogenous variables. There are $p$ autoregressive (AR) terms $v_{t-i}, q$ moving average (MA) terms $\epsilon_{t-i}, P$ seasonal

autoregressive (SAR) terms $v_{t-i \cdot s}$ with periodicity of $s$, and $Q$ seasonal moving average (SMA) terms $\epsilon_{t-i \cdot s}$ with periodicity of $s$ with the coefficients $\alpha_{i}, \beta_{i}, \alpha_{i \cdot s}$, and $\beta_{i \cdot s}$, respectively. In other words, the terms $v_{t-i}$ are lagged values of $v_{t}$ and $\epsilon_{t-i}$ Gaussian white noise error terms. The impact of the exogenous variables on price volatility is estimated by the parameter vector $\gamma$ using R (R Core Team, 2015).

\subsection{Summary Statistics}

Our data for the two Danish areas (Western Denmark, DK1 and Eastern Denmark, DK2) consist of hourly area prices (in $€ / M W h$ ), forecasted hourly wind power production (in $\mathrm{MW}$ ), forecasted hourly demand (in MW), and hourly cross-border flows between zones DK1-NO2, DK1-SE3, and DK2-SE4 (in MW) in the day-ahead spot market (data source Nord Pool Spot, 2016). We ignore Danish solar power because of its negligible capacity (Energinet.dk, 2014). For Germany (DE), we use hourly German prices (in €/MWh, Epex Spot, 2016), forecasted hourly wind and solar power production (in MW, EEX Transparency, 2016), forecasted hourly demand (in MW, ENTSO-E, 2016), and hourly cross-border flows between Germany and France (in MW, ENTSO-E, 2016). We account for fuel prices by including the daily natural gas spot price (in $€ / M W h$, at the NetConnect Germany hub, Bloomberg 
L.P., 2016). The dataset spans 1 January 2010 to 31 December 2014 and 1 January 2012 to 31 December 2014 for Denmark and Germany, respectively. The dataset for Germany is restricted by public data on cross-border flows.

Because prices are calculated by the exchanges, there are no measurement uncertainties or gaps. We employ VRE and demand forecasts for modelling instead of realised values because only forecasts are available for market participants when determining their bids to the day-ahead market. Thus, prices and volatility are affected by bidding decisions, which might have been different under perfect knowledge of forecast errors. For Germany, there are a few missing days in the ENTSO-E demand forecast time series; for these, we use realised values. Following the convention of the exchanges, we also divide the dataset into three blocks called off-peak 1 hours (from 12 AM to 9 AM), peak hours (9 AM to 9 PM), and off-peak 2 hours (9 PM to 12 AM).

Our measure of price volatility for day $d$ in Equation (1) is the logarithm of the standard deviation calculated from hourly prices $p_{h}$ and the average daily price $p_{d}=\frac{1}{24} \sum_{h=1}^{24} p_{h}$, i.e.,

$$
v_{d}=\ln \left(\sqrt{\frac{1}{24} \sum_{h=1}^{24}\left(p_{h}-p_{d}\right)^{2}}\right) .
$$

As an example of longer time windows, we consider weekly price volatility, which is computed from daily average prices $p_{d}$ and weekly average prices $p_{w}=\frac{1}{7} \sum_{d=1}^{7} p_{d}$.

$$
v_{w}=\ln \left(\sqrt{\frac{1}{7} \sum_{d=1}^{7}\left(p_{d}-p_{w}\right)^{2}}\right)
$$

We take the natural logarithm to make the time series stationary and to improve the model fit. Also, all exogenous variables $x_{t}$ in Equation (1) except for cross-border flows are transformed into natural logarithm form, and, thus, their coefficients $\gamma$ can be interpreted as elasticities. This assumption of constant elasticity between the exogenous variables and price volatility is more reasonable than assuming that changes in demand, for example, lead to equal changes in price volatility at different demand levels. Because cross-border flows take positive and negative values depending on the direction of the flow, we scale the figures by $1000 \mathrm{MW}$ to obtain values close to those of the logarithmic variables.

Figures 1a, 1b, and 1c show the average hourly price profile for DK1, DK2, and DE, respectively, resulting from demand patterns. During morning and evening high-load hours, the price is usually driven by thermal plants with higher marginal costs of production. In 
low-load times, such as night time, prices are set by thermal plants lower in the merit order. On the other hand, Figures 2a, 2b, and 2c show how the daily volatility of DK1, DK2, and DE prices has developed from 2010 to 2014, respectively. There is no clear increasing or decreasing trend in the price volatility of the areas, but the average volatility of Danish prices is lower than that of Germany.

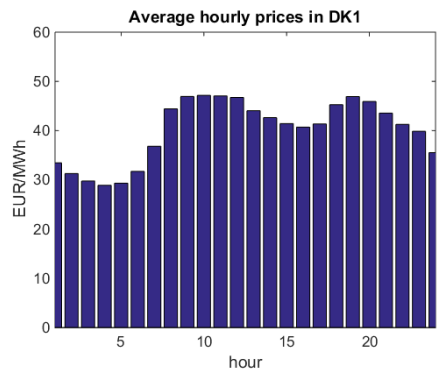

(a) DK1.

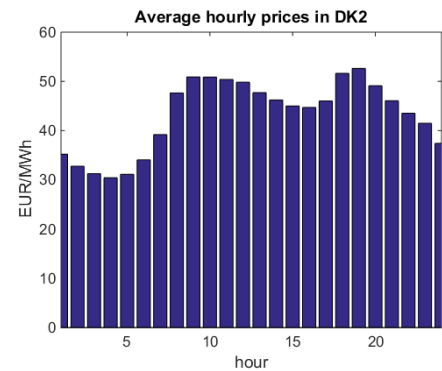

(b) DK2.

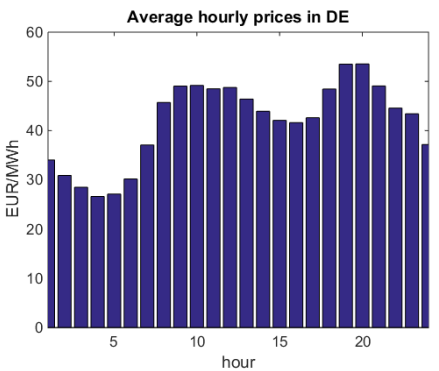

(c) DE.

Figure 1: Average hourly electricity prices for DK1, DK2, and DE from 2010 to 2014.

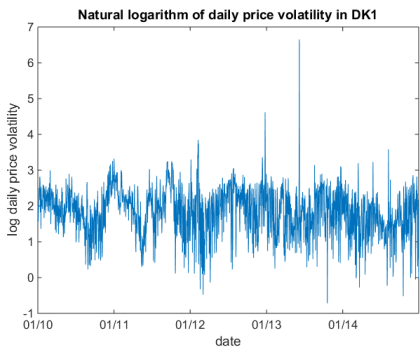

(a) DK1.

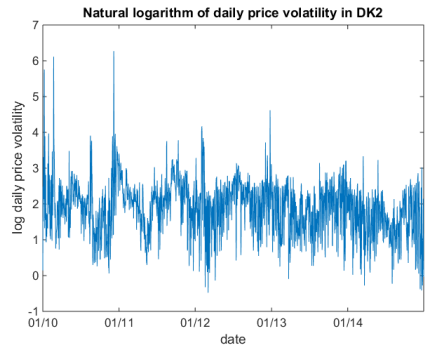

(b) DK2.

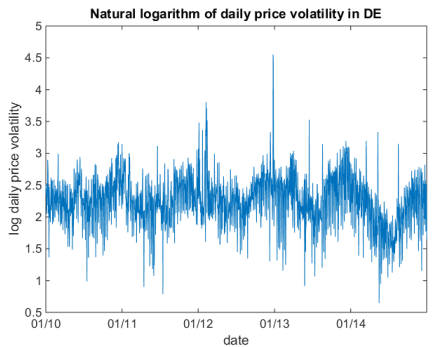

(c) DE.

Figure 2: The natural logarithm of daily price volatility of DK1, DK2, and DE prices from 2010 to 2014.

Figures $3 \mathrm{a}$ and $3 \mathrm{~b}$ confirm that Danish wind power peaks in the afternoon. In turn, Figure 3c shows that the production of German wind power is highest at night. The solar power profile in Germany is similar in each month with production only from 6 AM to 8 PM (Figure 4). We define the wind and solar power penetration during period $t$ as the share of average wind or solar power generation $\left(\right.$ wind $_{t}$, solar $\left.t\right)$ of the average demand $\left(\right.$ load $\left._{t}\right)$ during that period $t$.

$$
\text { wind_pen }_{t}=\frac{\text { wind }_{t}}{\text { load }_{t}} \text { and solar_pen } t=\frac{\text { solar }_{t}}{\operatorname{load}_{t}}
$$

\subsection{Stability Checks}

We confirm the stationarity of the time series by applying the augmented Dickey-Fuller (ADF) test. Table 11 in the Appendix shows that all daily time series pass the test at the 


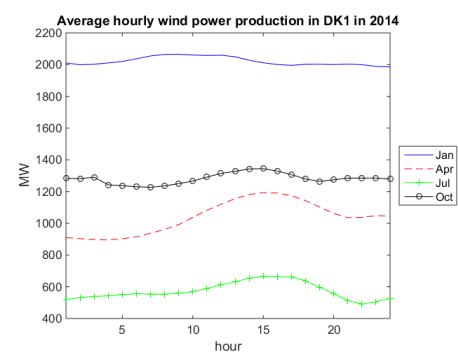

(a) DK1.

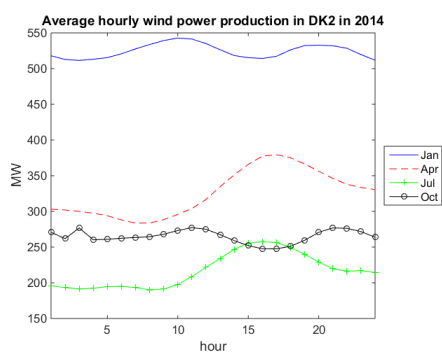

(b) DK2.

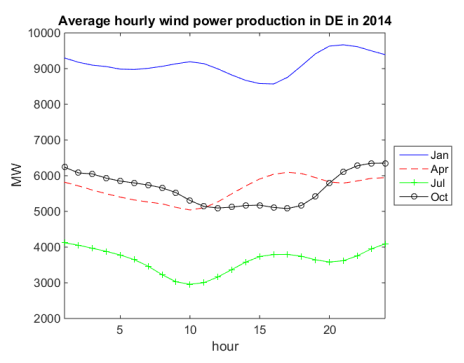

(c) DE.

Figure 3: Average hourly wind power in DK1, DK2, and DE in selected months in 2014.

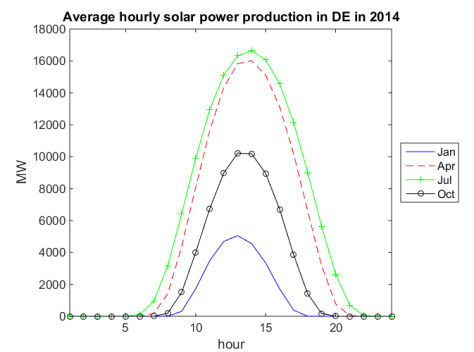

Figure 4: Average hourly solar power in DE in selected months in 2014.

10\% level until lag 15 except for German solar power, solar power penetration, and gas price, which are differenced to make them stationary. For weekly data, since the gas price, Danish exports, German wind and solar power, and their penetration fail the test already at low lags, we difference these time series. Table 12 shows that all time series pass the test after differencing except for weekly average solar power generation and penetration, which reduces the robustness of the results on their impact. In the regressions, we will use the differenced variables prefixed with $\Delta$ whenever necessary. For the notation, please refer to Table 1.

Autocorrelation (ACF) and partial autocorrelation functions (PACF) of the dependent variable in Equation (1) can be used to specify the order $(p, q)(P, Q)[s]$ of the model. The ACF and PACF of daily price volatility time series from DK1 and DK2 in Figures 5a, 5b, $5 \mathrm{c}$, and 5d, respectively, and from DE in Figures 5e and $5 \mathrm{f}$ have high peaks at the first lag and then near multiples of seven indicating a weekly pattern in price volatility (Shumway and Stoffer, 2011). All autocorrelation functions have a downward trend as older data is less relevant.

For both Denmark and Germany, we select the model (1) by stepwise addition of independent variables starting from a $\operatorname{SARMA}(1,0)(1,0)[7]$ model, as indicated by the ACF and PACF plots. In the selection process, we omit all exogenous variables $x_{t}$ and require all coefficients $\alpha$ and $\beta$ to be statistically significant at the $5 \%$ level. If a variable in a particular model $(\mathrm{p}, \mathrm{q})(\mathrm{P}, \mathrm{Q})$ becomes statistically insignificant, then we do not add new variables because they are likely to be insignificant, too. Also, if the addition of a new variable does 


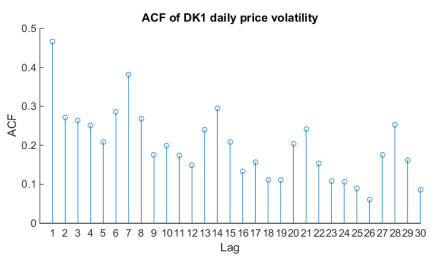

(a) ACF of DK1 price volatility.

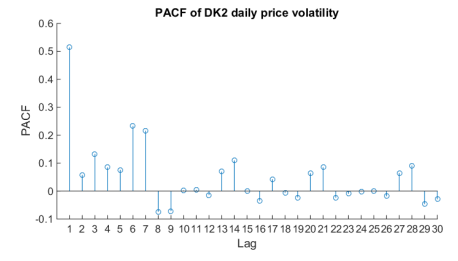

(d) PACF of DK2 price volatility.

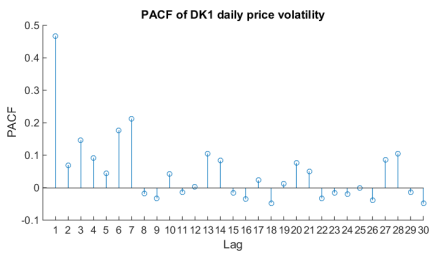

volatility.

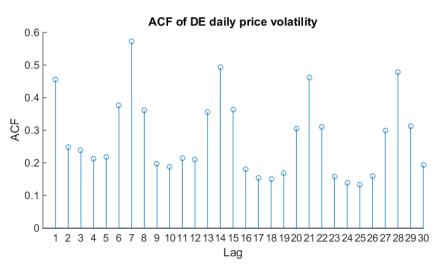

(e) ACF of DE price volatility. ity. ity.

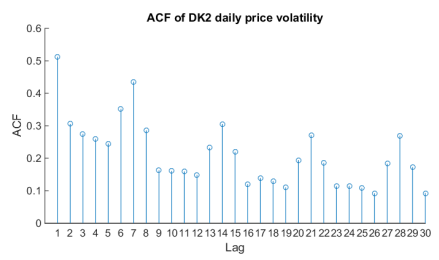

(c) ACF of DK2 price volatil-

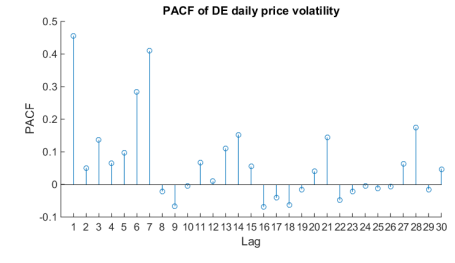

(f) PACF of DE price volatil-

Figure 5: ACF and PACF plots of DK1, DK2, and DE daily price volatility.

not improve the Akaike Information Criterion (AIC) compared to the previous model, then we stop. To compare the candidates obtained in this process, we assess the AIC score, perform the Ljung-Box (L-B) test for residual autocorrelation, and examine the Q-Q, ACF, and PACF plots of the residuals of the models. Because of the large number of observations, we can expect to obtain unbiased estimators and residuals with little serial correlation. The model selection results are reported in Tables 13-15 of the Appendix, where we have omitted models that fail improve the AIC score or have insignificant variables.

We note that the optimal fit would be obtained if model (1) were to be specified separately for each subset of exogenous variables $x_{t}$. However, very different specifications could make it difficult to compare the effect of the exogenous variables. Therefore, we present results for alternative model specifications in Tables 16-18 of the Appendix to see the sensitivity of the results obtained using the above process.

\section{Results}

\subsection{Daily Volatility}

We run separate regressions for both Danish areas, DK1 and DK2, and Germany, DE, to estimate the impact of different explanatory variables on the corresponding area price volatility. For all areas, we obtain the following SARMA $(2,1)(2,1)[7]$ model (see Table 13 for model search iterations)

$$
v_{d}=\alpha_{0}+\alpha_{1} v_{d-1}+\alpha_{2} v_{d-2}+\alpha_{7} v_{d-7}+\alpha_{14} v_{d-14}+\epsilon_{d}+\beta_{1} \epsilon_{d-1}+\beta_{7} \epsilon_{d-7} .
$$




\begin{tabular}{|c|c|}
\hline Variable & Explanation \\
\hline$v_{d}$ & Standard deviation of hourly prices on day $d(€ / \mathrm{MWh})$ \\
\hline$p_{d}^{o p 1}$ & Average off-peak 1 prices on day $d(€ / \mathrm{MWh})$ \\
\hline$p_{d}^{o p 2}$ & Average off-peak 2 prices on day $d(€ / \mathrm{MWh})$ \\
\hline & Average peak prices on day $d(€ / M W h)$ \\
\hline wind $_{d}$ & Average wind power on day $d(\mathrm{MW})$ \\
\hline $\operatorname{wind}_{d}^{o p 1}$ & Average off-peak 1 wind power on day $d(\mathrm{MW})$ \\
\hline wind $_{d}^{o p 2}$ & Average off-peak 2 wind power on day $d(\mathrm{MW})$ \\
\hline $\operatorname{wind}_{d}^{p}$ & Average peak wind power on day $d(\mathrm{MW})$ \\
\hline wind_pen $_{d}$ & Average wind power penetration on day $d$ \\
\hline wind_pen ${ }_{d}^{o p 1}$ & Average off-peak 1 wind power penetration on day $d$ \\
\hline wind_pen $_{d}^{o p 2}$ & Average off-peak 2 wind power penetration on day $d$ \\
\hline wind_pen $_{d}^{p}$ & Average peak wind power penetration on day $d$ \\
\hline $\operatorname{solar}_{d}$ & Average solar power on day $d(\mathrm{MW})$ \\
\hline $\operatorname{solar}_{d}^{p}$ & Average peak solar power on day $d(\mathrm{MW})$ \\
\hline solar_pen $_{d}$ & Average solar power penetration on day $d$ \\
\hline solar_pen ${ }_{d}^{p}$ & Average peak solar power penetration on day $d$ \\
\hline vre $_{d}$ & Average wind and solar power on day $d(\mathrm{MW})$ \\
\hline $\operatorname{vre}_{d}^{p}$ & Average peak wind and solar power on day $d(\mathrm{MW})$ \\
\hline vre_pen $_{d}$ & Average wind and solar power penetration on day $d$ \\
\hline vre_pen ${ }_{d}^{p}$ & Average peak wind and solar power penetration on day $d$ \\
\hline $\operatorname{exim}_{d}^{o p 1}$ & Average off-peak 1 export/import on day $d(\mathrm{GW})$ \\
\hline $\operatorname{exim}_{d}^{o p 2}$ & Average off-peak 2 export/import on day $d(\mathrm{GW})$ \\
\hline $\operatorname{exim}_{d}^{p}$ & Average peak export/import on day $d(\mathrm{GW})$ \\
\hline$g a s_{d}$ & Average spot gas price on day $d(€ / M W h)$ \\
\hline & Standard deviation of daily average prices during week $w$ (€/MWh) \\
\hline $\operatorname{wind}_{w}$ & Average wind power during week $w(\mathrm{MW})$ \\
\hline$w_{i n d}^{s t d}$ & Standard deviation of average daily wind power outputs during week $w$ (MW) \\
\hline wind_pen $_{w}$ & Average wind power penetration during week $w$ \\
\hline $\operatorname{solar}_{w}$ & Average solar power during week $w(\mathrm{MW})$ \\
\hline solar_pen $_{w}$ & Average solar power penetration during week $w$ \\
\hline vre $_{w}$ & Average wind and solar power during week $w(\mathrm{MW})$ \\
\hline$v r e_{w}^{s t d}$ & Standard deviation of average daily wind and solar power outputs during week $w(\mathrm{MW})$ \\
\hline vre_pen $_{w}$ & Average wind and solar power penetration during week $w$ \\
\hline $\operatorname{exim}_{w}$ & Average export/import during week $w(\mathrm{GW})$ \\
\hline$g a s_{w}$ & Average gas price during week $w(€ / M W h)$ \\
\hline
\end{tabular}

Table 1: Exogenous variables in our models. We take the natural logarithm of all variables except exim ${ }_{d}^{o p 1}$, $\operatorname{exim}_{d}^{o p 2}, \operatorname{exim}_{d}^{p}$, and $\operatorname{exim}_{w}$. 
The $\mathrm{AR}(1)$ and $\mathrm{AR}(2)$ terms account for short-term price volatility development, and the $\operatorname{SAR}(1)$ and $\operatorname{SAR}(2)$ terms deal with the weekly seasonality in the data. Adding MA(1) and SMA(1) terms provides stochastic parts to the development of the price volatility and improves the fit of the model. Various exogenous variables with the associated parameters, i.e., the term $\gamma^{\top} x_{t}$ in Equation (1), are added to the right-hand side of this model. For example, model 1 for DK1 in Table 2 is

$$
v_{d}=\alpha_{0}+\alpha_{1} v_{d-1}+\alpha_{2} v_{d-2}+\alpha_{7} v_{d-7}+\alpha_{14} v_{d-14}+\epsilon_{d}+\beta_{1} \epsilon_{d-1}+\beta_{7} \epsilon_{d-7}+\gamma \text { wind } d_{d}
$$

In Tables 2 and 3, the main finding is that the coefficient for wind power, wind $d_{d}$, in DK1 at -0.0892 and in DK2 at -0.0696 in model 1 is statistically significantly different from zero at the $1 \%$ level according to a $Z$-test. For both areas, the interpretation is that increasing the amount of daily wind power production by $1 \%$ decreases the daily volatility of prices by $0.06-0.09 \% .^{1}$ The effect is slightly stronger in DK1 than DK2, most likely due to the combination of higher wind power capacity and lower demand in DK1. Moreover, model 2

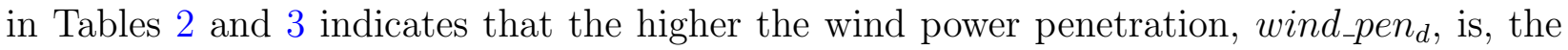
lower the price volatility.

Mauritzen (2010) runs similar regressions with a $\operatorname{SARMA}(2,2)(1,2)[7]$ model. Our result for DK1 is in line with Mauritzen, but his estimate for the coefficient for DK2 is not statistically significant. The most probable explanation for the difference is that his data span 2002 to 2007, whereas our more recent dataset includes higher wind power capacity in DK2, and, thus, its market impact is likely to be stronger.

In models 3 and 4, we control for exports to and imports from hydro-dominant Sweden and Norway in morning off-peak, peak, and evening off-peak hours $\left(\operatorname{exim}_{d}^{o p 1}\right.$, exim ${ }_{d}^{p}$, and exim ${ }_{d}^{o p 2}$, respectively) and find nearly unchanged coefficients for wind power in both areas. The same is true for wind power penetration in model 5. Because the spot market transmission flows are likely to be endogenous with the price volatility, we cannot draw causal conclusions about their impact (Mauritzen, 2013). However, model 4 for DK1 suggests that exports during morning off-peak hours are positively correlated with daily price volatility, but, during peak hours, the correlation is negative. This is explained by the fact that greater difference between the peak and off-peak hours implies high exports (imports) in the off-peak (peak) hours. By contrast, for DK2, the impact of cross-border exchange is inconclusive in model 4, which can

\footnotetext{
${ }^{1}$ Consider a model $\ln y=\alpha+\beta^{\top} z+\gamma \ln x$. Fixing $z$, with two different values, $x_{2}$ and $x_{1}$, we have $\ln y_{2}-\ln y_{1}=\gamma\left(\ln x_{2}-\ln x_{1}\right) \Leftrightarrow \ln \frac{y_{2}}{y_{1}}=\gamma \ln \frac{x_{2}}{x_{1}} \Leftrightarrow \frac{y_{2}-y_{1}}{y_{1}}=\left(\frac{x_{2}}{x_{1}}\right)^{\gamma}-1$. Numerically, the approximation $\frac{y_{2}-y_{1}}{y_{1}} \approx \gamma\left(\frac{x_{2}-x_{1}}{x_{1}}\right)$ deviates from the true value of $\frac{y_{2}-y_{1}}{y_{1}}$ by less than 0.004 percentage points when $\frac{x_{2}-x_{1}}{x_{1}}=$ 0.01 and $|\gamma| \leq 0.5$.
} 
be attributed to the fact that DK2 is connected only to the SE4 bidding area with practically no hydro reservoirs, whereas DK1 is connected to large reservoirs in bidding areas NO2 and SE3 (Nord Pool Spot, 2014). These results are in line with Green and Vasilakos (2012), who find that Denmark exports excess wind power to Norway and Sweden in off-peak hours, in particular, and that the volume of this exchange is higher for DK1 than DK2.

With model 6, we test for the impact of the first difference of natural gas prices, $\Delta g_{a s_{d}}$, and find no statistically significant effect on DK1 and DK2 daily price volatility. We note that the daily changes in natural gas spot prices are small, and, thus, they are unlikely to affect short-term bidding behaviour significantly. Moreover, some producers may have longer-term gas contracts instead of relying on spot gas.

\begin{tabular}{|c|c|c|c|c|c|c|}
\hline Variable Model & Model 1 & Model 2 & Model 3 & Model 4 & Model 5 & Model 6 \\
\hline wind $_{d}$ & $\begin{array}{l}-0.0892 \\
(0.0158)\end{array}$ & & $\begin{array}{l}-0.0731 \\
(0.0193)\end{array}$ & $\begin{array}{l}-0.0906 \\
(0.0194)\end{array}$ & & $\begin{array}{l}-0.0889 \\
(0.0158)\end{array}$ \\
\hline wind_pen $_{d}$ & & $\begin{array}{l}-0.0867 \\
(0.0160)\end{array}$ & & & $\begin{array}{l}-0.0879 \\
(0.0198)\end{array}$ & \\
\hline $\operatorname{exim}_{d}^{o p 1}$ & & & $\begin{array}{l}0.0641^{b} \\
(0.0328)\end{array}$ & $\begin{array}{c}0.1004 \\
(0.0331)\end{array}$ & $\begin{array}{c}0.1017 \\
(0.0334)\end{array}$ & \\
\hline $\operatorname{exim}_{d}^{p}$ & & & $\begin{array}{l}0.0783^{a} \\
(0.0374)\end{array}$ & $\begin{array}{l}-0.0806 \\
(0.0308)\end{array}$ & $\begin{array}{l}-0.0850 \\
(0.0307)\end{array}$ & \\
\hline $\operatorname{exim}_{d}^{o p 2}$ & & & $\begin{array}{l}-0.2241 \\
(0.0305)\end{array}$ & & & \\
\hline$\Delta g a s_{d}$ & & & & & & $\begin{array}{l}0.3324^{c} \\
(0.4080)\end{array}$ \\
\hline$\alpha_{0}$ & 2.3918 & 1.7080 & 2.2531 & 2.3566 & 1.6605 & 2.3649 \\
\hline$\alpha_{1}$ & 1.2236 & 1.2210 & 1.2546 & 1.2450 & 1.2437 & 1.2210 \\
\hline$\alpha_{2}$ & -0.2526 & -0.2504 & -0.2787 & -0.2728 & -0.2718 & -0.2510 \\
\hline$\alpha_{7}$ & 1.0711 & 1.0706 & 1.0811 & 1.0751 & 1.0747 & 1.0699 \\
\hline$\alpha_{14}$ & -0.0726 & -0.0721 & -0.08232 & -0.0769 & -0.0766 & -0.0731 \\
\hline$\beta_{1}$ & -0.8635 & -0.8632 & -0.8698 & -0.8669 & -0.8666 & -0.8625 \\
\hline$\beta_{7}$ & -0.9804 & -0.9804 & -0.9825 & -0.9792 & -0.9791 & -0.9803 \\
\hline AIC & 2878.82 & 2881.50 & 2820.47 & 2871.62 & 2873.72 & 2879.57 \\
\hline L-B & 30 & 30 & 28 & 30 & 30 & 30 \\
\hline
\end{tabular}

Table 2: The effect of different explanatory variables on DK1 daily price volatility. All coefficients are statistically significant at the $1 \%$ level unless otherwise noted.

Increasing the daily German wind power, wind $d_{d}$, by $1 \%$ increases the daily volatility of German prices by $0.03 \%$ as indicated by model 1 in Table 4 . The result is in line with Ketterer (2014) whose estimate from a rolling regression ranges from $0 \%$ to approximately $0.05 \%$. However, when the first difference in daily solar power production, $\Delta$ solar $_{d}$, increases by $1 \%$, the daily volatility of German prices decreases by $0.04 \%$ in model 2 . This indicates that also a higher absolute level of solar power leads to lower daily price volatility. Model 


\begin{tabular}{|c|c|c|c|c|c|c|}
\hline $\begin{array}{lll} & \text { Model } \\
\text { Variable } & \end{array}$ & Model 1 & Model 2 & Model 3 & Model 4 & Model 5 & Model 6 \\
\hline wind $_{d}$ & $\begin{array}{l}-0.0696 \\
(0.0147)\end{array}$ & & $\begin{array}{l}-0.0517 \\
(0.0164)\end{array}$ & $\begin{array}{l}-0.0604 \\
(0.0165)\end{array}$ & & $\begin{array}{l}-0.0686 \\
(0.0146)\end{array}$ \\
\hline wind_pen $_{d}$ & & $\begin{array}{l}-0.0654 \\
(0.0149)\end{array}$ & & & $\begin{array}{l}-0.0544 \\
(0.0167)\end{array}$ & \\
\hline $\operatorname{exim}_{d}^{o p 1}$ & & & $\begin{array}{l}-0.0171^{a} \\
(0.0418)\end{array}$ & $\begin{array}{r}-0.0070^{a} \\
(0.0430)\end{array}$ & $\begin{array}{r}-0.0119^{a} \\
(0.0433)\end{array}$ & \\
\hline $\operatorname{exim}_{d}^{p}$ & & & $\begin{array}{c}0.1462 \\
(0.0481)\end{array}$ & $\begin{array}{l}-0.0474^{a} \\
(0.0416)\end{array}$ & $\begin{array}{l}-0.0516^{a} \\
(0.0416)\end{array}$ & \\
\hline $\operatorname{exim}_{d}^{o p 2}$ & & & $\begin{array}{l}-0.3060 \\
(0.0395)\end{array}$ & & & \\
\hline$\Delta g a s_{d}$ & & & & & & $\begin{array}{r}-0.3214^{a} \\
(0.4306)\end{array}$ \\
\hline$\alpha_{0}$ & 2.2065 & 1.7110 & 2.0966 & 2.1547 & 1.7289 & 2.2035 \\
\hline$\alpha_{1}$ & 1.2329 & 1.2302 & 1.2677 & 1.2313 & 1.2289 & 1.2305 \\
\hline$\alpha_{2}$ & -0.2685 & -0.2660 & -0.2960 & -0.2679 & -0.2658 & -0.2673 \\
\hline$\alpha_{7}$ & 1.1054 & 1.1066 & 1.1078 & 1.1045 & 1.1060 & 1.1046 \\
\hline$\alpha_{14}$ & -0.1058 & -0.1069 & -0.1081 & -0.1050 & -0.1063 & -0.1050 \\
\hline$\beta_{1}$ & -0.8378 & -0.8371 & -0.8504 & -0.8332 & -0.8329 & -0.8368 \\
\hline$\beta_{7}$ & -0.9886 & -0.9904 & -0.9912 & -0.9875 & -0.9894 & -0.9875 \\
\hline AIC & 3159.90 & 3163.27 & 3106.16 & 3162.16 & 3164.78 & 3134.09 \\
\hline L-B & 30 & 30 & 30 & 30 & 30 & 9 \\
\hline
\end{tabular}

Table 3: The effect of different explanatory variables on DK2 daily price volatility. All coefficients are statistically significant at the $1 \%$ level unless otherwise noted.

3 confirms the signs of the coefficients in the presence of both wind and solar power. Yet, when we combine wind and solar power in variable $v_{r} e_{d}$ in model 4 , the coefficient becomes statistically insignificant, which is likely to be caused by the opposing effects of wind and solar power. We arrive at the same conclusions by using the penetration of wind, solar, or the combined generation, i.e., wind_pen , solar_pen $_{d}$, and vre_pen $_{d}$, respectively, as an exogenous variable in models 5-7.

Controlling for the cross-border flow between Germany and France in model 8 keeps the coefficients for wind w $_{\text {and }} \Delta$ solar $_{d}$ close to the earlier estimates. Positive and negative coefficients for the morning off-peak and peak hour transmission flow $\left(\operatorname{exim}_{d}^{o p 1}\right.$ and $\left.\operatorname{exim}_{d}^{p}\right)$, respectively, suggest higher price volatility when exports change to imports during the day. Finally, model 9 shows, in agreement with the result for Denmark, that the first difference of gas prices, $\Delta g_{a s_{d}}$, does not have an impact on the daily volatility of German prices.

For all areas, the AIC scores in Table 13 improve after adding the exogenous variables to Equation (5). In Tables 2-4, we report the lag at which the Ljung-Box test fails at a $1 \%$ significance level. The models for DK2 have some autocorrelation at lag 9, but the models for DK1 and DE perform well with all lags. However, Figures 6a-6c show that the ACF plot of the residuals of model 1 for DK1 and DK2 and model 4 for Germany stay within the 
95\% confidence interval with very few exceptions. As a cross-check, we estimate alternative models (see Table 16) and find that the estimated parameters for wind and solar power are robust with respect to the specification.

\begin{tabular}{|c|c|c|c|c|c|c|c|c|c|}
\hline $\begin{array}{lll} & \text { Model } \\
\text { Variable } & \end{array}$ & Model 1 & Model 2 & Model 3 & Model 4 & Model 5 & Model 6 & Model 7 & Model 8 & Model 9 \\
\hline wind $_{d}$ & $\begin{array}{l}0.0328^{a} \\
(0.0146)\end{array}$ & & $\begin{array}{l}0.0296^{a} \\
(0.0147)\end{array}$ & & & & & $\begin{array}{l}0.0367^{a} \\
(0.0147)\end{array}$ & $\begin{array}{l}0.0320^{a} \\
(0.0148)\end{array}$ \\
\hline$\Delta$ solar $_{d}$ & & $\begin{array}{r}-0.0379^{a} \\
(0.0191)\end{array}$ & $\begin{array}{l}-0.0350^{b} \\
(0.0191)\end{array}$ & & & & & $\begin{array}{l}-0.0205^{c} \\
(0.0191)\end{array}$ & $\begin{array}{l}-0.0339^{b} \\
(0.0191)\end{array}$ \\
\hline vre $_{d}$ & & & & $\begin{array}{l}0.0187^{c} \\
(0.0227)\end{array}$ & & & & & \\
\hline wind_pen $_{d}$ & & & & & $\begin{array}{l}0.0350^{a} \\
(0.0147)\end{array}$ & & & & \\
\hline$\Delta$ solar_pen $_{d}$ & & & & & & $\begin{array}{l}-0.0466^{a} \\
(0.0187)\end{array}$ & & & \\
\hline vre_pen $_{d}$ & & & & & & & $\begin{array}{l}0.0203^{c} \\
(0.0220)\end{array}$ & & \\
\hline $\operatorname{exim}_{d}^{o p 1}$ & & & & & & & & $\begin{array}{c}0.0853 \\
(0.0117)\end{array}$ & \\
\hline $\operatorname{exim}_{d}^{p}$ & & & & & & & & $\begin{array}{l}-0.0781 \\
(0.0137)\end{array}$ & \\
\hline $\operatorname{exim}_{d}^{o p 2}$ & & & & & & & & $\begin{array}{l}0.0211^{c} \\
(0.0134)\end{array}$ & \\
\hline$\Delta g a s_{d}$ & & & & & & & & & $\begin{array}{l}-0.3840^{c} \\
(0.3308)\end{array}$ \\
\hline$\alpha_{0}$ & 1.9167 & 2.2698 & 2.0009 & 2.0691 & 2.3221 & 2.2432 & 2.2764 & 1.9351 & 1.9710 \\
\hline$\alpha_{1}$ & 1.1513 & 1.1657 & 1.1613 & 1.1459 & 1.1525 & 1.1675 & 1.1532 & 1.1508 & 1.1615 \\
\hline$\alpha_{2}$ & -0.1622 & -0.1752 & -0.1711 & -0.1576 & -0.1633 & -0.1773 & -0.1637 & -0.1623 & -0.1716 \\
\hline$\alpha_{7}$ & 1.1764 & 1.1724 & 1.1749 & 1.1717 & 1.1770 & 1.1722 & 1.1737 & 1.1686 & 1.1788 \\
\hline$\alpha_{14}$ & -0.1766 & -0.1725 & -0.1752 & -0.1719 & -0.1772 & -0.1724 & -0.1739 & -0.1688 & -0.1789 \\
\hline$\beta_{1}$ & -0.9165 & -0.9168 & -0.9190 & -0.9108 & -0.9167 & -0.9163 & -0.9140 & -0.9276 & -0.9189 \\
\hline$\beta_{7}$ & $-0.9896^{c}$ & -0.9911 & -0.9870 & -0.9885 & -0.9890 & -0.9910 & -0.9898 & -0.9888 & -0.9914 \\
\hline AIC & 487.73 & 488.60 & 486.92 & 492.33 & 487.13 & 486.39 & 491.88 & 434.13 & 486.92 \\
\hline L-B & 30 & 30 & 30 & 30 & 30 & 30 & 30 & 30 & 30 \\
\hline
\end{tabular}

Table 4: The effect of different explanatory variables on DE price volatility. All coefficients are statistically significant at the $1 \%$ level unless otherwise noted.

\subsection{Analysis of Intraday Effects}

Next, we investigate further why wind power decreases the daily volatility in Denmark but increases it in Germany. Given the hourly price profiles in Figures 1a, 1b, and 1c, the volatility-increasing impact of wind power can be explained if prices in off-peak 1 and 2 decrease more than during peak hours, leading to divergent prices. On the other hand, the volatility will decrease if peak prices decrease more than off-peak prices so that the hourly price profile becomes flatter.

To test these possibilities, we perform similar regressions as in the previous section for each block, except that the logarithm of the standard deviation of hourly prices, $v_{d}$, is replaced by the logarithm of the average price of each block $\left(p_{d}^{o p 1}, p_{d}^{p}\right.$, and $\left.p_{d}^{o p 2}\right)$. Model iteration 


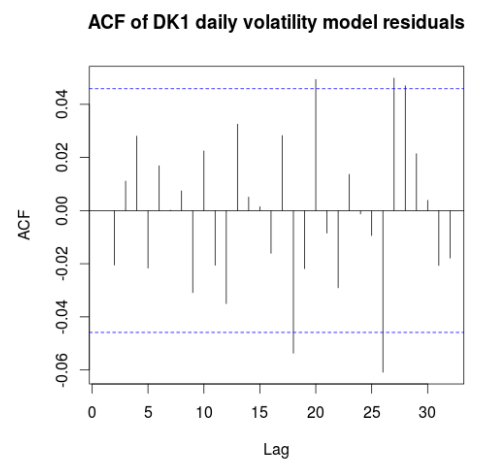

(a) DK1.

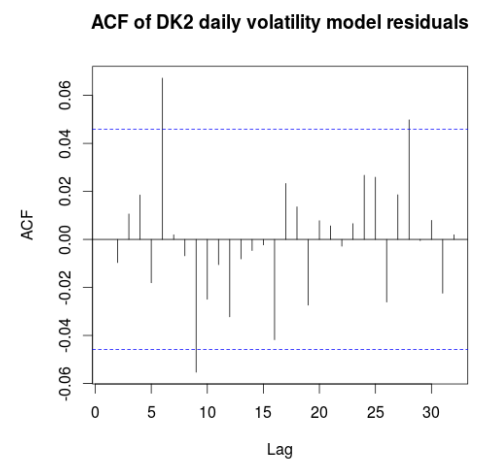

(b) DK2.

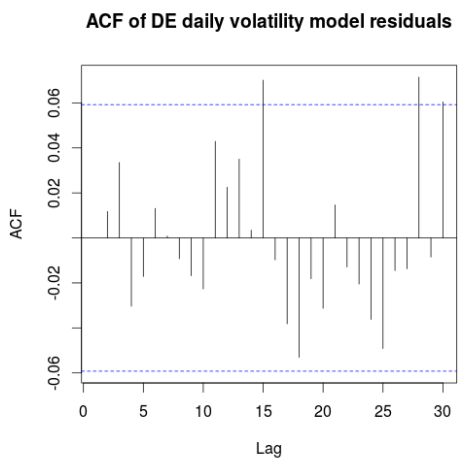

(c) DE.

Figure 6: ACF plot of the residuals of the daily price volatility model 1 for DK1, DK2 and DE.

steps in Table 14 show that the best models for DK1, DK2 and DE are $\operatorname{SARMA}(2,1)(2,1)[7]$, $\operatorname{SARMA}(1,2)(1,2)[7]$, and SARMA $(1,1)(1,2)[7]$, respectively, using data for peak hours.

However, the addition of exogenous variables to these model causes many variables become statistically insignificant (see Table 17). Therefore, we step down to a simpler $\operatorname{SARMA}(2,1)(1,1)[7]$ model, which for DK1, DK2, and DE differs only by 2.13, 21.64, and 5.25 from the best models in terms of AIC score, respectively. Moreover, the results for different areas can be more readily compared by using a common model. Nevertheless, we consider the best area models in Table 17 of the Appendix. The final SARMA $(2,1)(1,1)[7]$ model is as follows

$$
p_{d}^{b}=\alpha_{0}+\alpha_{1} p_{d-1}^{b}+\alpha_{2} p_{d-2}^{b}+\alpha_{7} p_{d-7}^{b}+\epsilon_{d}+\beta_{1} \epsilon_{d-1}+\beta_{7} \epsilon_{d-7},
$$

where $b$ is the block $\in\{o p 1, o p 2, p\}$. Similar to the model in Equation (6), the exogenous variables are added to the right-hand side of Equation (7). We note that the instances with a negative average price for a block are removed from our dataset. For DK1, DK2, and DE, there are 13, 10, and 15 such off-peak blocks, respectively. Since the total number of observations is 1813, 1816, and 1081, respectively, we expect that the impact of removing these observations on the coefficients for off-peak blocks is slightly positive at most.

Tables 5 and 6 have the results of the regressions for DK1 and DK2, respectively. The coefficient for average wind power during peak hours, wind $d_{d}^{p}$, for example, is at the intersection of row wind $_{d}$ and the column "Peak". Thus, the coefficients for peak-hour wind power, wind $d_{d}^{p}$, are -0.0726 and -0.0570 , respectively, which differ by only $0.01-0.04$ units from those for morning and evening off-peak hours, wind $d_{d}^{o p 1}$ and $w i n d_{d}^{o p 2}$, respectively. Hence, increasing wind power in the peak hours, for example, by $1 \%$ causes a $0.07 \%$ and $0.06 \%$ decline in the average peak price in DK1 and DK2, respectively. Our approximate estimate of the average 
price-decreasing impact of doubling wind power penetration, wind_pen , at $_{6} \%$ is comparable to Jónsson et al. (2010) who estimate that increasing wind power penetration from $20 \%$ up to $40 \%$ decreases DK1 prices approximately $10 \% .^{2}$

Figure 3a shows that in Denmark there is a peak in wind output during peak hours, which amplifies the total impact of wind power on peak hours relative to off-peak hours. Combined with the small difference between peak and off-peak hour coefficients, this supports the hypothesis that wind power contributes to the flattening of the intraday price profile by decreasing peak prices more than off-peak prices in absolute terms.

Moreover, exchange with the hydro-dominant Nordic countries may contribute to similar flattening of the intraday price curve as the coefficients for peak hour cross-border flows $\operatorname{exim}_{d}^{p}$ are negative at -0.10 and they differ only slightly from those for morning and evening off-peak hours, exim ${ }_{d}^{o p 1}$ and $\operatorname{exim}_{d}^{o p 2}$, respectively. As the capacities of the associated transmission lines exceed the average DK1 and DK2 wind power forecast in our dataset substantially, the impact of cross-border exchange on DK1 and DK2 electricity prices is significant.

Because the estimated coefficients for the impact of wind power and export in different blocks have higher absolute values for DK1 than DK2, daily DK1 prices are more likely to drop more than daily DK2 prices for a comparable increase in wind power or exports. In agreement with the results in Section 4.1, daily DK1 price volatility is likely to drop more than daily DK2 price volatility due to lower absolute level of prices.

\begin{tabular}{|c|c|c|c|c|c|c|}
\hline Variable $\quad$ Block & Off-peak 1 & Off-peak 1 & Peak & Peak & Off-peak 2 & Off-peak 2 \\
\hline wind $_{d}$ & $\begin{array}{l}-0.1090 \\
(0.0092)\end{array}$ & & $\begin{array}{l}-0.0726 \\
(0.0052)\end{array}$ & & $\begin{array}{l}-0.0647 \\
(0.0051)\end{array}$ & \\
\hline wind_pen $_{d}$ & & $\begin{array}{l}-0.1153 \\
(0.0092)\end{array}$ & & $\begin{array}{l}-0.0791 \\
(0.0052)\end{array}$ & & $\begin{array}{l}-0.0667 \\
(0.0051)\end{array}$ \\
\hline exim $_{d}$ & $\begin{array}{l}-0.1454 \\
(0.0183)\end{array}$ & $\begin{array}{l}-0.1373 \\
(0.0182)\end{array}$ & $\begin{array}{l}-0.1073 \\
(0.0091)\end{array}$ & $\begin{array}{l}-0.0996 \\
(0.0091)\end{array}$ & $\begin{array}{l}-0.0865 \\
(0.0088)\end{array}$ & $\begin{array}{l}-0.0854 \\
(0.0087)\end{array}$ \\
\hline$\alpha_{0}$ & 4.1465 & 3.3179 & 4.1694 & 3.5878 & 4.0406 & 3.5412 \\
\hline$\alpha_{1}$ & 1.1511 & 1.1505 & 1.1730 & 1.1687 & 1.0622 & 1.0626 \\
\hline$\alpha_{2}$ & -0.1922 & -0.1904 & -0.2240 & -0.2195 & -0.0933 & -0.0922 \\
\hline$\alpha_{7}$ & 0.9475 & 0.9456 & 0.9535 & 0.9533 & 0.9704 & 0.9683 \\
\hline$\beta_{1}$ & -0.7910 & -0.7951 & -0.7615 & -0.7632 & -0.7222 & -0.7254 \\
\hline$\beta_{7}$ & -0.8791 & -0.8835 & -0.7990 & -0.8082 & -0.9359 & -0.9391 \\
\hline AIC & 792.47 & 776.51 & -1197.78 & -1229.52 & -1331.94 & -1343.87 \\
\hline L-B & 30 & 30 & 4 & 4 & 4 & 4 \\
\hline
\end{tabular}

Table 5: The effect of different explanatory variables on DK1 price level in each block. All coefficients are statistically significant at the $1 \%$ level.

\footnotetext{
${ }^{2}$ Although our estimate is computed using the exact formula $\frac{y_{2}-y_{1}}{y_{1}}=\left(\frac{x_{2}}{x_{1}}\right)^{\gamma}-1$, the estimate is approximate as the true coefficient, $\gamma$, is likely to be different at different wind power penetration levels.
} 


\begin{tabular}{|c|c|c|c|c|c|c|}
\hline Variable Block & Off-peak 1 & Off-peak 1 & Peak & Peak & Off-peak 2 & Off-peak 2 \\
\hline wind $_{d}$ & $\begin{array}{l}-0.0796 \\
(0.0068)\end{array}$ & & $\begin{array}{l}-0.0570 \\
(0.0042)\end{array}$ & & $\begin{array}{l}-0.0543 \\
(0.0045)\end{array}$ & \\
\hline wind_pen $_{d}$ & & $\begin{array}{l}-0.0813 \\
(0.0068)\end{array}$ & & $\begin{array}{l}-0.0596 \\
(0.0042)\end{array}$ & & $\begin{array}{l}-0.0557 \\
(0.0045)\end{array}$ \\
\hline exim $_{d}$ & $\begin{array}{l}-0.0910 \\
(0.0205)\end{array}$ & $\begin{array}{l}-0.0890 \\
(0.0205)\end{array}$ & $\begin{array}{l}-0.0658 \\
(0.0122)\end{array}$ & $\begin{array}{l}-0.0615 \\
(0.0122)\end{array}$ & $\begin{array}{l}-0.0471 \\
(0.0122)\end{array}$ & $\begin{array}{l}-0.0451 \\
(0.0122)\end{array}$ \\
\hline$\alpha_{0}$ & 3.8882 & 3.3140 & 4.0757 & 3.6436 & 3.9298 & 3.5348 \\
\hline$\alpha_{1}$ & 1.1808 & 1.1804 & 1.2429 & 1.2405 & 1.0707 & 1.0698 \\
\hline$\alpha_{2}$ & -0.2303 & -0.2301 & -0.2909 & -0.2889 & -0.1073 & -0.1070 \\
\hline$\alpha_{7}$ & 0.9019 & 0.8978 & 0.9608 & 0.9605 & 0.9627 & 0.9641 \\
\hline$\beta_{1}$ & -0.7384 & -0.7401 & -0.7500 & -0.7506 & -0.7208 & -0.7217 \\
\hline$\beta_{7}$ & -0.7794 & -0.7766 & -0.7912 & -0.7949 & -0.9186 & -0.9220 \\
\hline AIC & 623.24 & 617.20 & -1033.78 & -1049.23 & -842.63 & -850.23 \\
\hline L-B & 30 & 30 & 4 & 6 & 5 & 5 \\
\hline
\end{tabular}

Table 6: The effect of different explanatory variables on DK2 price level in each block. All coefficients are statistically significant at the $1 \%$ level.

For Germany, Table 7 shows that the coefficients for wind power are $-0.1530,-0.3073$, and -0.1874 for peak $\left(w i n d_{d}^{p}\right)$, morning off-peak $\left(w i n d_{d}^{o p 1}\right)$, and evening off-peak hours $\left(\right.$ wind $\left._{d}^{\text {op } 2}\right)$, respectively. Similar coefficients are confirmed by wind power penetration, wind_pen ${ }_{d}$, too. The fact that the coefficients for morning and evening off-peak hours in Germany are more negative than the coefficient for peak hours indicates that the supply curves for offpeak hours are more sensitive than the supply curves for peak hours. Indeed, Paraschiv et al. (2014) find that the impact of wind power on German prices has been up to 3.5 times higher in the morning off-peak than in the peak hours, but the difference has decreased over time. Thus, if there is an increase in wind power production during off-peak hours, then prices will fall more than in peak hours for a comparative increase in wind output. This is true especially in morning off-peak hours where the impact is twofold.

In addition, the fact that German wind power peaks during off-peak hours (Figure 3c) suggests that German off-peak prices can decrease more compared to peak prices in absolute terms, thereby resulting in higher daily price volatility in keeping with the findings of Section 4.1. In practice, this means that morning off-peak prices, in particular, can crash due to the combination of wind power production and low demand. By contrast, peak-hour prices with high demand decrease only slightly.

Increasing the first difference of average German solar power production, $\Delta$ solar $_{d}$, by $1 \%$ decreases peak prices by $0.05 \%$ as indicated by Table 7 . Furthermore, when we add peak-hour wind and solar power, the parameter estimates for the average combined generation, vre $_{d}$, and its penetration, $v_{r}$ pen $_{d}$, are approximately twice as large as the coefficients for wind power, which suggests an equal contribution from solar power. The inconclusive impact of 
combined VRE generation on German daily price volatility in Section 4.1 can be explained by the fact that the coefficient for wind power in morning off-peak hours at -0.3073 and the coefficient for combined generation in peak hours at -0.3602 are rather close to each other, thereby indicating that these blocks decrease by nearly the same amount. However, because the coefficient for wind power in the evening off-peak hours is less negative at -0.1874 , the overall impact of VRE generation on daily price volatility in Germany is likely to be slightly positive on average because evening off-peak hours diverge, which is also supported by the average hourly prices in Figure 1c.

All the coefficients for cross-border flows between Germany and France, exim , $_{\text {, are pos- }}$ itive. Germany is a net exporter over these transmission lines meaning that the higher the export from Germany to France, the higher the German prices. Similar to wind power, the higher coefficients for off-peak hours, exim ${ }_{d}^{o p 1}$ and $\operatorname{exim}_{d}^{o p 2}$, than for peak hours, $\operatorname{exim}_{d}^{p}$, imply a higher price sensitivity during the off-peak hours. However, the magnitudes of the coefficients for exim, are relatively small, which indicates that the cross-border exchange with France has a limited correlation with the German price level. Indeed, the possibilities to balance excess VRE generation are limited as the capacity of these transmission lines is only $30 \%$ of average VRE forecast in our dataset and the flows to hydro-dominant Austria and Switzerland approach congestion as the VRE penetration grows (Zugno et al., 2013).

The AIC scores of the models for Denmark and Germany improve significantly when external variables are added to the model in Equation (7). Ljung-Box tests for some models fail already at low lags, which indicate that there is some serial correlation in our models. We estimated models with additional AR and MA terms, which pass the Ljung-Box test up to lag 30, and find that the estimated parameters for DK1, DK2, and DE external variables in Tables 5, 6, and 7 are robust. Also, Table 17 shows that the results hold with the best area models, too, although they improve the AIC scores only for Germany.

\subsection{Weekly Volatility}

We now extend the analysis to a weekly horizon by specifying a model that includes the weekly price volatility in Equation (3) and the weekly average wind, solar, and combined production. The general model is

$$
v_{w}=\alpha_{0}+\sum_{i=1}^{p} \alpha_{i} v_{w-i}+\sum_{i=1}^{q} \beta_{i} \epsilon_{w-i}+\sum_{i=1}^{P} \alpha_{i \cdot s} v_{w-i \cdot s}+\sum_{i=1}^{Q} \beta_{i \cdot s} \epsilon_{w-i \cdot s}+\epsilon_{w}+\gamma^{\top} x_{w}
$$

Unlike the daily models, weekly volatility is affected by several factors such as power plant and transmission line availability and changes in bidding behaviour, which may not have any seasonality. Therefore, we start with the simplest models such as AR(1) and MA(1) 


\begin{tabular}{|c|c|c|c|c|c|c|c|c|c|c|}
\hline $\begin{array}{cc}\text { Variable } & \text { Block } \\
\end{array}$ & Off-peak 1 & Off-peak 1 & Peak & Peak & Peak & Peak & Peak & Peak & Off-peak 2 & Off-peak 2 \\
\hline wind $_{d}$ & $\begin{array}{l}-0.3073 \\
(0.0156)\end{array}$ & & $\begin{array}{l}-0.1530 \\
(0.0090)\end{array}$ & & & & & & $\begin{array}{l}-0.1874 \\
(0.0079)\end{array}$ & \\
\hline wind_pen $d$ & & $\begin{array}{l}-0.3243 \\
(0.0151)\end{array}$ & & $\begin{array}{l}-0.1667 \\
(0.0087)\end{array}$ & & & & & & $\begin{array}{l}-0.1915 \\
(0.0078)\end{array}$ \\
\hline$\Delta$ solar $_{d}$ & & & & & $\begin{array}{l}-0.0528 \\
(0.0142)\end{array}$ & & & & & \\
\hline$\Delta s o l a r_{-} p e n_{d}$ & & & & & & $\begin{array}{l}-0.0807 \\
(0.0138)\end{array}$ & & & & \\
\hline vre $_{d}$ & & & & & & & $\begin{array}{l}-0.3602 \\
(0.0158)\end{array}$ & & & \\
\hline vre_pen $_{d}$ & & & & & & & & $\begin{array}{l}-0.3984 \\
(0.0145)\end{array}$ & & \\
\hline $\operatorname{exim}_{d}$ & $\begin{array}{c}0.0436 \\
(0.0107)\end{array}$ & $\begin{array}{c}0.0440 \\
(0.0101)\end{array}$ & $\begin{array}{c}0.0187 \\
(0.0072)\end{array}$ & $\begin{array}{c}0.0193 \\
(0.0070)\end{array}$ & $\begin{array}{l}0.0096^{c} \\
(0.0082)\end{array}$ & $\begin{array}{l}0.0107^{c} \\
(0.0081)\end{array}$ & $\begin{array}{c}0.0284 \\
(0.0066)\end{array}$ & $\begin{array}{c}0.0286 \\
(0.0061)\end{array}$ & $\begin{array}{c}0.0444 \\
(0.0059)\end{array}$ & $\begin{array}{c}0.0422 \\
(0.0058)\end{array}$ \\
\hline$\alpha_{0}$ & 5.8789 & 2.5388 & 4.9809 & 3.2649 & 3.7043 & 3.7006 & 7.0370 & 3.0252 & 5.1723 & 3.1432 \\
\hline$\alpha_{1}$ & -0.5556 & -0.5669 & 0.9730 & 0.9757 & 0.9555 & 0.9735 & 0.8819 & 0.8652 & 0.5906 & 0.6052 \\
\hline$\alpha_{2}$ & 0.2948 & 0.2815 & $-0.1192^{a}$ & $-0.1206^{a}$ & $-0.1394^{b}$ & $-0.1497^{a}$ & $-0.0801^{c}$ & $-0.0717^{c}$ & $0.0991^{c}$ & $0.0924^{c}$ \\
\hline$\alpha_{7}$ & 0.9167 & 0.9184 & 0.9338 & 0.9327 & 0.9280 & 0.9283 & 0.9322 & 0.9272 & 0.9614 & 0.9586 \\
\hline$\beta_{1}$ & 0.9225 & 0.9229 & -0.6736 & -0.6763 & -0.6016 & -0.6135 & -0.6452 & -0.6335 & $-0.3428^{a}$ & $-0.3561^{a}$ \\
\hline$\beta_{7}$ & -0.7339 & -0.7575 & -0.5912 & -0.6016 & -0.6093 & -0.6152 & -0.5658 & -0.5863 & -0.8166 & -0.8258 \\
\hline $\mathrm{AIC}$ & 601.62 & 550.09 & -223.51 & -282.05 & -2.58 & -22.43 & -379.56 & -534.03 & -829.03 & -856.04 \\
\hline L-B & 4 & 4 & 30 & 30 & 30 & 30 & 14 & 14 & 30 & 30 \\
\hline
\end{tabular}

Table 7: The effect of different explanatory variables on DE price level in each block. All coefficients are statistically significant at the $1 \%$ the level unless otherwise noted.

but try also a four-week, i.e., monthly, seasonality (Weron, 2014). Table 15 reports the model iterations. For the Danish areas, models with the monthly seasonality show the best performance, but they are found to be statistically insignificant for Germany. AR(1), which is the best model for Germany, fails the Ljung-Box test with Danish data already at low lags. Therefore, we run SARMA $(1,0)(0,1)[4]$ for Danish and AR(1) for German data:

$$
\begin{aligned}
& v_{w}=\alpha_{0}+\alpha_{1} v_{w-1}+\beta_{4} \epsilon_{w-4}+\epsilon_{w} \\
& v_{w}=\alpha_{0}+\alpha_{1} v_{w-1}+\epsilon_{w} .
\end{aligned}
$$

In Equations (9) and (10), the $\mathrm{AR}(1)$ term approximates the current volatility with the previous one. In addition, an $\operatorname{SMA}(1)$ term in the Danish model (9) deals with monthly seasonality.

We find that increasing the weekly average wind power, wind $d_{w}$, by $1 \%$ increases the weekly volatility of DK1 prices by $0.18 \%$ as indicated by model 1 in Table 8 . For DK2, the effect is inconclusive in model 1 in Table 9, which may be attributed to lower wind power capacity. These results apply for weekly wind power penetration, wind_pen $w_{w}$, in model 2. Furthermore, controlling for the first difference of weekly average exports, $\Delta$ exim $_{w}$, in models 3 and 4 does not change the conclusions for wind power and its penetration. However, the standard deviation of daily average wind power outputs, i.e., the intermittency of daily wind 
power increases the weekly price volatility by $0.37 \%$ and $0.18 \%$ both in DK1 and DK2 in model 5, respectively. Similar to the daily volatility results, model 6 shows that the change in weekly average natural gas price, $\Delta g a s_{w}$, does not have an impact on the weekly price volatility. Table 18 confirms the conclusions using an alternative $\operatorname{ARMA}(1,1)$ model.

\begin{tabular}{|c|c|c|c|c|c|c|}
\hline Variable $\quad$ Model & Model 1 & Model 2 & Model 3 & Model 4 & Model 5 & Model 6 \\
\hline wind $_{w}$ & $\begin{array}{c}0.1820 \\
(0.0711)\end{array}$ & & $\begin{array}{c}0.1636^{a} \\
(0.0790)\end{array}$ & & & \\
\hline wind_pen $_{w}$ & & $\begin{array}{c}0.2098 \\
(0.0723)\end{array}$ & & $\begin{array}{l}0.1969^{a} \\
(0.0803)\end{array}$ & & \\
\hline$\Delta e x_{w}$ & & & $\begin{array}{l}0.0410^{b} \\
(0.0761)\end{array}$ & $\begin{array}{l}0.0288^{b} \\
(0.0759)\end{array}$ & & \\
\hline $\operatorname{wind}_{w}^{s t d}$ & & & & & $\begin{array}{c}0.3653 \\
(0.0731)\end{array}$ & \\
\hline$\Delta g a s_{w}$ & & & & & & $\begin{array}{c}0.4286^{b} \\
(0.5424)\end{array}$ \\
\hline$\alpha_{0}$ & $0.4021^{b}$ & 1.8344 & $0.5223^{b}$ & 1.8186 & $-0.5931^{b}$ & 1.6036 \\
\hline$\alpha_{1}$ & 0.3073 & 0.3059 & 0.3043 & 0.3032 & 0.3030 & 0.3298 \\
\hline$\beta_{4}$ & 0.1990 & 0.1989 & 0.2027 & 0.2018 & 0.1877 & 0.2100 \\
\hline AIC & 427.39 & 425.81 & 428.26 & 426.55 & 409.97 & 434.39 \\
\hline L-B & 30 & 30 & 30 & 30 & 30 & 30 \\
\hline
\end{tabular}

Table 8: The effect of different explanatory variables on DK1 weekly price volatility. All coefficients are statistically significant at the $1 \%$ level unless otherwise noted.

In Germany, increasing the first difference of weekly average wind power by $1 \%$ increases weekly price volatility by $0.11 \%$ as suggested by the coefficient for $\Delta$ wind $_{w}$ in Table 10 . This is supported by the comparative effect of the first difference of weekly average wind power penetration, $\Delta$ wind_pen $_{w}$, in model 2. The positive coefficients for the first differences indicate that higher weekly average wind power is associated with higher weekly price volatility in Germany. However, models 3 and 4 are inconclusive regarding the impact of the first difference in weekly average solar power, $\Delta$ solar $_{w}$, and its penetration, $\Delta$ solar_pen $_{w}$, because the coefficients are statistically insignificant. As in the daily volatility model, the effect is likely negative because the coefficient estimates are negative. Consequently, the impact of weekly average VRE generation, $v r e_{w}$, and its penetration, vre_pen ${ }_{w}$, is inconclusive in models 5 and 6 , respectively. Nevertheless, increasing the change in the standard deviation of VRE generation, $\Delta v r e_{w}^{s t d}$, by $1 \%$ increases weekly price volatility by $0.11 \%$ in model 7 . In models 8 and 9 , the inclusion of weekly average exports, exim ${ }_{w}$, does not change the earlier conclusions on the impact of weekly wind and solar power. Counterintuitively, we find a negative impact of the first difference of weekly average gas price, $\Delta g_{a s_{w}}$, on the weekly volatility of prices, but the very high coefficient, -2.0427 , makes the result unreliable. 


\begin{tabular}{|c|c|c|c|c|c|c|}
\hline Variable Model & Model 1 & Model 2 & Model 3 & Model 4 & Model 5 & Model 6 \\
\hline wind $_{w}$ & $\begin{array}{l}0.0621^{b} \\
(0.0720)\end{array}$ & & $\begin{array}{l}0.0045^{b} \\
(0.0746)\end{array}$ & & & \\
\hline wind_pen $_{w}$ & & $\begin{array}{l}0.0465^{b} \\
(0.0729)\end{array}$ & & $\begin{array}{l}-0.0100^{b} \\
(0.0752)\end{array}$ & & \\
\hline$\Delta e x i m_{w}$ & & & $\begin{array}{l}0.2457^{a} \\
(0.1125)\end{array}$ & $\begin{array}{l}0.2533^{a} \\
(0.1122)\end{array}$ & & \\
\hline $\operatorname{wind}_{w}^{\text {std }}$ & & & & & $\begin{array}{l}0.1842^{a} \\
(0.0749)\end{array}$ & \\
\hline$\Delta g a s_{w}$ & & & & & & $\begin{array}{l}0.2222^{b} \\
(0.6070)\end{array}$ \\
\hline$\alpha_{0}$ & 1.3173 & 1.7411 & 1.6084 & 1.6122 & $0.7595^{a}$ & 1.6318 \\
\hline$\alpha_{1}$ & 0.3445 & 0.3465 & 0.3246 & 0.3247 & 0.3459 & 0.3238 \\
\hline$\beta_{4}$ & $0.1710^{a}$ & $0.1744^{a}$ & $0.1642^{a}$ & $0.1664^{a}$ & $0.1500^{a}$ & $0.1555^{a}$ \\
\hline AIC & 498.58 & 498.92 & 479.82 & 479.81 & 493.48 & 485.21 \\
\hline L-B & 30 & 30 & 30 & 30 & 30 & 30 \\
\hline
\end{tabular}

Table 9: The effect of different explanatory variables on DK2 weekly price volatility. All coefficients are statistically significant at the $1 \%$ level unless otherwise noted.

\begin{tabular}{|c|c|c|c|c|c|c|c|c|c|c|}
\hline $\begin{array}{ll}\text { Variable } & \text { Model }\end{array}$ & Model 1 & Model 2 & Model 3 & Model 4 & Model 5 & Model 6 & Model 7 & Model 8 & Model 9 & Model 10 \\
\hline$\Delta$ wind $_{w}$ & $\begin{array}{l}0.1051^{b} \\
(0.0591)\end{array}$ & & & & & & & $\begin{array}{l}0.1095^{b} \\
(0.0597)\end{array}$ & & \\
\hline$\Delta$ wind_pen $_{w}$ & & $\begin{array}{l}0.1407^{a} \\
(0.0593)\end{array}$ & & & & & & & & \\
\hline$\Delta \operatorname{solar}_{w}$ & & & $\begin{array}{l}-0.1707^{c} \\
(0.1130)\end{array}$ & & & & & & $\begin{array}{l}-0.1793^{c} \\
(0.1137)\end{array}$ & \\
\hline$\Delta$ solar_pen $_{w}$ & & & & $\begin{array}{l}-0.1432^{c} \\
(0.1122)\end{array}$ & & & & & & \\
\hline$v e_{w}$ & & & & & $\begin{array}{l}0.1322^{c} \\
(0.1174)\end{array}$ & & & & & \\
\hline vre_pen $_{w}$ & & & & & & $\begin{array}{c}0.1513^{c} \\
(0.1096)\end{array}$ & & & & \\
\hline$\Delta v r e_{w}^{s t d}$ & & & & & & & $\begin{array}{l}0.1083^{a} \\
(0.0551)\end{array}$ & & & \\
\hline $\operatorname{exim}_{w}$ & & & & & & & & $\begin{array}{c}0.0282^{c} \\
(0.0368)\end{array}$ & $\begin{array}{c}0.0289^{c} \\
(0.0383)\end{array}$ & \\
\hline$\Delta g a s_{w}$ & & & & & & & & & & $\begin{array}{r}-2.0427^{a} \\
(0.8334)\end{array}$ \\
\hline$\alpha_{0}$ & 1.9668 & 1.9669 & 1.9676 & 1.9676 & $0.7636^{c}$ & 2.2393 & 1.9663 & 1.9406 & 1.9408 & 1.9669 \\
\hline$\alpha_{1}$ & $0.1676^{a}$ & $0.1610^{b}$ & 0.2058 & 0.2070 & $0.1726^{a}$ & $0.1759^{a}$ & $0.1699^{a}$ & $0.1559^{b}$ & $0.1963^{a}$ & $0.2019^{a}$ \\
\hline$\overline{\mathrm{AIC}}$ & 170.97 & 168.44 & 171.96 & 172.6 & 173.68 & 173.05 & 170.28 & 172.39 & 173.39 & 168.32 \\
\hline L-B & 30 & 30 & 30 & 30 & 30 & 30 & 30 & 30 & 30 & 30 \\
\hline
\end{tabular}

Table 10: The effect of different explanatory variables on German weekly price volatility. All coefficients are statistically significant at the $1 \%$ level unless otherwise noted. 
The results for Danish and German VRE generation intermittency, wind ${ }_{w}^{\text {std }}$ and $\Delta v r e_{w}^{\text {std }}$, respectively, can be explained by day-to-day horizontal parallel shifts of the supply curve. When the installed VRE capacity increases, the available supply increases and the parallel shifts are larger, which contributes to the growing weekly volatility. In both countries, the impact can be amplified by highly clustered wind power farms (Elberg and Hagspiel, 2015). However, the average weekly solar power is not found to contribute to the weekly price volatility, which can be explained by the peak-price-decreasing impact of solar power in Germany.

\section{Conclusions}

Our analyses suggest that wind and solar power production have statistically and economically significant effects on day-ahead price volatility in Denmark and Germany. In the short run, Danish daily price volatility is lower when there is more wind power production. By contrast, wind power increases the daily price volatility in Germany. However, our results are aligned with those of Jónsson et al. (2010), Mauritzen (2010), and Ketterer (2014). In Denmark, the price-decreasing impact of wind power is distributed evenly during different times of day, and there is a peak in average wind power production during peak hours. In Germany, off-peak hours are most sensitive to downward pressure in prices, and wind power is, on average, highest during these hours. Also, we find evidence that the contrasting impact of wind power on price volatility is partly due to the fact that Denmark has access to large hydropower reservoirs in the Nordic countries, whereas Germany's cross-border transmission lines are small relative to the size of its power system and it has limited access to flexible generation capacity. On the other hand, solar power is produced only during peak hours, which decreases daily volatility by decreasing high peak hour prices in Germany. Because wind and solar power have opposite effects on daily price volatility, results on their combined impact are inconclusive.

Our weekly results suggest that the standard deviation of daily average VRE generation increases the weekly volatility of Danish and German prices. These impacts can be attributed to the high day-to-day variability of wind and solar power production. Moreover, the higher the average weekly wind power, the higher the weekly price volatility.

In periods with high price volatility, producers and consumers need to optimise their generation and demand allocation to maximise their profits and to minimise their costs, respectively. From the power system point of view, the adoption of more VRE requires mechanisms to cope with intermittent supply and to decrease balancing costs (Kunz, 2013). The results for Denmark suggest that access to flexible capacity via adequate transmission capacity can reduce short-term volatility. In addition, measures such as i) capacity payments 
that incentivise flexible plants (Hach and Spinler, 2016), ii) dispersing wind and solar power farms (Elberg and Hagspiel, 2015), and iii) integration of adjacent markets (Farahmand et al., 2012) can be utilised. On the consumer side, enhanced understanding of the causes of volatility can be used to design tariffs that incentivise demand response (Dupont et al., 2014), which is likely to mitigate the costs of balancing caused by the intermittency of VRE.

The limitations of our distributed lag models need to be recognised. First, they estimate a single coefficient to represent the impact of VRE generation on price volatility even if the impact is more dynamic and dependent on the market situation. We have studied only the whole dataset, while the impacts may change over time. Second, the high frequency of trading in electricity markets means that time-series models may not capture processes driving price formation very accurately, which causes errors in the estimated coefficients for VRE. Nevertheless, our checks corroborate the robustness of our findings based on standard time-series methods.

A subject for further research could be to use different modelling techniques. Similar to Ketterer (2014), the impact of wind power on Danish price volatility could be established using a GARCH model. On the other hand, German price volatility could be explored as a function of time and VRE penetration using the non-parametric regression model of Jónsson et al. (2010). Also, the link between VRE generation levels and supply curve elasticities can be established more formally using real supply and demand curve data (see Dillig et al., 2016) or agent-based or complementarity models. Another avenue for future research is to estimate the impact of VRE generation on price volatility in other renewable-rich locations such as Spain, Ireland, and California. Moreover, as the absolute value of the VRE forecast errors is likely to increase when the VRE capacity increases, trading volumes and prices on various intraday markets are subject to change.

\section{Acknowledgements}

This research has been supported by funding from the STEEM project of the Aalto Energy Efficiency programme.

\section{References}

Barthelmie, R., Courtney, M., Højstrup, J., and Larsen, S. (1996). Meteorological aspects of offshore wind energy: Observations from the Vindeby wind farm. Journal of Wind Engineering and Industrial Aerodynamics, 62(2-3):191-211.

Boomsma, T. K., Juul, N., and Fleten, S.-E. (2014). Bidding in sequential electricity markets: The Nordic case. European Journal of Operational Research, 238:797809. 
Bloomberg L.P. (2016). NetConnect Germany spot gas prices. Retrieved from Bloomberg database, ticker EEXGNCGR.

Dillig, M., Jung, M., and Karl, J. (2016). The impact of renewables on electricity prices in Germany - An estimation based on historic spot prices in the years 2011 - 2013. Renewable and Sustainable Energy Reviews, 57:7-15.

Dupont, B., Jonghe, C. D., Olmos, L., and Belmans, R. (2014). Demand response with locational dynamic pricing to support the integration of renewables. Energy Policy, 67:344354.

EEX Transparency (2016). Ex-ante Solar \& Wind Power Production. https: //www. eex-transparency.com/homepage/power/germany/production/usage/ solar-wind-power-production.

ENTSO-E Transparency (2016). Scheduled Commercial Exchanges. https://transparency.entsoe.eu/transmission-domain/r2/ scheduledCommercialExchangesDayAhead/show.

ENTSO-E Transparency (2016). Total Load - Day Ahead / Actual. https://transparency . entsoe.eu/load-domain/r2/totalLoadR2/show.

Epex Spot (2016). Epex spot auction. https://www.epexspot.com/en/market-data/ dayaheadauction.

Egerer, J., Kunz, F., and von Hirschhausen, C. (2013). Development scenarios for the North and Baltic Seas Grid - A welfare economic analysis. Utilities Policy, 27:123-134.

Elberg, C. and Hagspiel, S. (2015). Spatial dependencies of wind power and interrelations with spot price dynamics. European Journal of Operational Research, 241(1):260-272.

Energinet.dk (2014). Solar power. http://www. energinet.dk/EN/KLIMA-OG-MILJOE/ Miljoerapportering/VE-produktion/Sider/Sol . aspx.

Energinet.dk (2015). Wind turbines reached record level in 2014. http://energinet.dk/ EN/El/Nyheder/Sider/Vindmoeller-slog-rekord-i-2014.aspx.

Farahmand, H., Aigner, T., Doorman, G., Korpas, M., and Huertas-Hernando, D. (2012). Balancing market integration in the Northern European continent: A 2030 case study. IEEE Transactions on Sustainable Energy, 3(4):918-930. 
Frömmel, M., Han, X., and Kratochvil, S. (2014). Modeling the daily electricity price volatility with realized measures. Energy Economics, 44:492-502.

Gelabert, L., Labandeira, X., and Linares, P. (2011). An ex-post analysis of the effect of renewables and cogeneration on Spanish electricity prices. Energy Economics, 33 S1:S59S65.

González-Aparicio, I. and Zucker, A. (2015). Impact of wind power uncertainty forecasting on the market integration of wind energy in Spain. Applied Energy, 159:334-349.

Green, R. and Vasilakos, N. (2010). Market behaviour with large amounts of intermittent generation. Energy Policy, 38(7):3211-3220.

Green, R. and Vasilakos, N. (2011). The long-term impact of wind power on electricity prices and generating power. ESRC Centre for Competition Policy Working Paper Series. Available at SSRN http://papers.ssrn. com/sol3/papers. cfm?abstract_id=1851311.

Green, R. and Vasilakos, N. (2012). Storing wind for a rainy day: What kind of electricity does Denmark export? The Energy Journal, 33(3):1-22.

Hach, D. and Spinler, S. (2016). Capacity payment impact on gas-fired generation investments under rising renewable feed-in - A real options analysis. Energy Economics, 53:270-280.

He, Y., Hildmann, M., and Andersson, G. (2012). Modeling the wind power in-feed in Germany by data decomposition and time series analysis. In Power and Energy Society General Meeting, 2012 IEEE, pages 1-8.

Holttinen, H. (2005). Hourly wind power variations in the Nordic countries. Wind Energy, $8(2): 173-195$.

Huber, M., Dimkova, D., and Hamacher, T. (2014). Integration of wind and solar power in Europe: Assessment of flexibility requirements. Energy, 69:236-246.

Jaehnert, S., Wolfgang, O., Farahmand, H., Vller, S., and Huertas-Hernando, D. (2013). Transmission expansion planning in Northern Europe in 2030 - Methodology and analyses. Energy Policy, pages 125-139.

Jónsson, T., Pinson, P., and Madsen, H. (2010). On the market impact of wind energy forecasts. The Energy Journal, 32(2):313-320.

Kalantzis, F. G. and Milonas, N. T. (2013). Analyzing the impact of futures trading on spot price volatility: Evidence from the spot electricity market in France and Germany. Energy Economics, 36:454-463. 
Ketterer, J. C. (2014). The impact of wind power generation on the electricity price in Germany. Energy Economics, 44:270-280.

Kunz, F. (2013). Improving congestion management: How to facilitate the integration of renewable generation in Germany. The Energy Journal, 34(4):55-78.

Mauritzen, J. (2010). What happens when it's windy in Denmark? An empirical analysis of wind power on price volatility in the Nordic electricity market. Discussion Papers 2010/18, Department of Business and Management Science, Norwegian School of Economics.

Mauritzen, J. (2013). Dead battery? Wind power, the spot market, and hydropower interaction in the Nordic electricity market. The Energy Journal, 34(1):103-123.

Mauritzen, J. (2015). Now or later? Trading wind power closer to real-time: How poorly designed subsidies can lead to higher balancing costs. The Energy Journal, 36(4):1-16.

Morales, J., Conejo, A., and Perez-Ruiz, J. (2011). Simulating the impact of wind production on locational marginal prices. IEEE Transactions on Power Systems, 26(2):820-828.

Mulder, M. and Scholtens, B. (2013). The impact of renewable energy on electricity prices in the Netherlands. Renewable Energy, 57:94-100.

Nord Pool Spot (2016). Historical market data. http://nordpoolspot.com/ historical-market-data/.

Nord Pool Spot (2014). Hydro reservoir. http://nordpoolspot.com/Market-data1/ Power-system-data/hydro-reservoir1/ALL/Hourly/?view=table.

Paraschiv, F., Erni, D., and Pietsch, R. (2014). The impact of renewable energies on EEX day-ahead electricity prices. Energy Policy, 73:196-210.

R Core Team (2015). R: A language and environment for statistical computing. R Foundation for Statistical Computing, Vienna, Austria. URL https://www.R-project.org/.

Shumway, R. H. and Stoffer, D. S. (2011). Time Series Analysis and Its Applications: With $R$ Examples. Springer-Verlag New York, 3rd edition.

von Hirschhausen, C. (2014). The German 'Energiewende' - An introduction. Economics of Energy \&6 Environmental Policy, 3(2):1-12.

Weron, R. (2014). Electricity price forecasting: A review of the state-of-the-art with a look into the future. International Journal of Forecasting, 30(4):1030-1081. 
Würzburg, K., Labandeira, X., and Linares, P. (2013). Renewable generation and electricity prices: Taking stock and new evidence for Germany and Austria. Energy Economics, 40 S1:S159-S171.

Yip, C. M. A., Gunturu, U. B., and Stenchikov, G. L. (2016). Wind resource characterization in the Arabian Peninsula. Applied Energy, 164:826-836.

Zugno, M., Pinson, P., and Madsen, H. (2013). Impact of wind power generation on European cross-border power flows. IEEE Transactions on Power Systems, 28:3566-3575. 


\section{Appendix A ADF Tests}

\begin{tabular}{|c|c|c|c|c|c|c|c|c|c|}
\hline Lag & \multicolumn{3}{|c|}{5} & \multicolumn{3}{|c|}{10} & \multicolumn{3}{|c|}{15} \\
\hline Variable Area & DK1 & DK2 & $\mathrm{DE}$ & DK1 & DK2 & $\mathrm{DE}$ & DK1 & DK2 & $\mathrm{DE}$ \\
\hline$v_{d}$ & 0.01 & 0.01 & 0.01 & 0.01 & 0.01 & 0.01 & 0.01 & 0.01 & 0.07 \\
\hline$p_{d}^{o p 1}$ & 0.01 & 0.01 & 0.01 & 0.01 & 0.01 & 0.01 & 0.01 & 0.01 & 0.01 \\
\hline$p_{d}^{o p 2}$ & 0.01 & 0.01 & 0.01 & 0.01 & 0.01 & 0.01 & 0.01 & 0.01 & 0.01 \\
\hline$p_{d}^{p}$ & 0.01 & 0.01 & 0.01 & 0.01 & 0.01 & 0.01 & 0.01 & 0.01 & 0.01 \\
\hline wind $_{d}$ & 0.01 & 0.01 & 0.01 & 0.01 & 0.01 & 0.01 & 0.01 & 0.01 & 0.01 \\
\hline wind $_{d}^{o p 1}$ & 0.01 & 0.01 & 0.01 & 0.01 & 0.01 & 0.01 & 0.01 & 0.01 & 0.01 \\
\hline wind $_{d}^{o p 2}$ & 0.01 & 0.01 & 0.01 & 0.01 & 0.01 & 0.01 & 0.01 & 0.01 & 0.01 \\
\hline $\operatorname{wind}_{d}^{p}$ & 0.01 & 0.01 & 0.01 & 0.01 & 0.01 & 0.01 & 0.01 & 0.01 & 0.01 \\
\hline wind_pen $_{d}$ & 0.01 & 0.01 & 0.01 & 0.01 & 0.01 & 0.01 & 0.01 & 0.01 & 0.01 \\
\hline wind_pen op 1 & 0.01 & 0.01 & 0.01 & 0.01 & 0.01 & 0.01 & 0.01 & 0.01 & 0.01 \\
\hline wind_pen $\stackrel{o p 2}{o p}$ & 0.01 & 0.01 & 0.01 & 0.01 & 0.01 & 0.01 & 0.01 & 0.01 & 0.01 \\
\hline wind_pen $_{d}^{p}$ & 0.01 & 0.01 & 0.01 & 0.01 & 0.01 & 0.01 & 0.01 & 0.01 & 0.01 \\
\hline solar $_{d}$ & & & 0.25 & & & 0.56 & & & 0.89 \\
\hline $\operatorname{solar}_{d}^{p}$ & & & 0.18 & & & 0.66 & & & 0.92 \\
\hline solar_pen $_{d}$ & & & 0.25 & & & 0.52 & & & 0.87 \\
\hline solar_pen $_{d}^{p}$ & & & 0.18 & & & 0.63 & & & 0.91 \\
\hline vre $_{d}$ & & & 0.01 & & & 0.01 & & & 0.01 \\
\hline $\operatorname{vre}_{d}^{p}$ & & & 0.01 & & & 0.01 & & & 0.01 \\
\hline 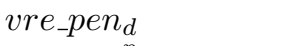 & & & 0.01 & & & 0.01 & & & 0.01 \\
\hline vre_pen ${ }_{d}^{p}$ & & & 0.01 & & & 0.01 & & & 0.01 \\
\hline $\operatorname{exim}_{d}^{o p 1}$ & 0.01 & 0.01 & 0.01 & 0.01 & 0.01 & 0.04 & 0.04 & 0.03 & 0.09 \\
\hline $\operatorname{exim}_{d}^{o p^{2}}$ & 0.01 & 0.01 & 0.01 & 0.01 & 0.01 & 0.01 & 0.02 & 0.01 & 0.03 \\
\hline $\operatorname{exim}_{d}^{p}$ & 0.01 & 0.01 & 0.01 & 0.01 & 0.01 & 0.01 & 0.01 & 0.01 & 0.01 \\
\hline$g a s_{d}$ & 0.19 & 0.19 & 0.15 & 0.40 & 0.40 & 0.37 & 0.35 & 0.35 & 0.36 \\
\hline$v_{w}$ & 0.01 & 0.01 & 0.01 & 0.04 & 0.01 & 0.32 & 0.03 & 0.03 & 0.44 \\
\hline wind $_{w}$ & 0.02 & 0.04 & 0.63 & 0.03 & 0.09 & 0.41 & 0.01 & 0.08 & 0.09 \\
\hline wind $_{w}^{s t d}$ & 0.01 & 0.01 & & 0.01 & 0.03 & & 0.03 & 0.18 & \\
\hline wind_pen $_{w}$ & 0.01 & 0.02 & 0.49 & 0.03 & 0.16 & 0.43 & 0.02 & 0.26 & 0.19 \\
\hline $\operatorname{solar}_{w}$ & & & 0.36 & & & 0.04 & & & 0.06 \\
\hline solar_pen $_{w}$ & & & 0.33 & & & 0.02 & & & 0.04 \\
\hline vre $_{w}$ & & & 0.03 & & & 0.42 & & & 0.22 \\
\hline$v r e_{w}^{s t d}$ & & & 0.17 & & & 0.58 & & & 0.11 \\
\hline vre_pen $_{w}$ & & & 0.02 & & & 0.41 & & & 0.25 \\
\hline $\operatorname{exim}_{w}$ & 0.36 & 0.18 & 0.08 & 0.24 & 0.12 & 0.09 & 0.20 & 0.09 & 0.08 \\
\hline$g a s_{w}$ & 0.48 & 0.48 & 0.65 & 0.09 & 0.09 & 0.42 & 0.08 & 0.08 & 0.43 \\
\hline
\end{tabular}

Table 11: Augmented Dickey-Fuller test p-values. All figures have been rounded to two decimal places. Empty cells indicate that the variable is not used for all areas. 


\begin{tabular}{|c|c|c|c|c|c|c|c|c|c|}
\hline Lag & \multicolumn{3}{|c|}{5} & \multicolumn{3}{|c|}{10} & \multicolumn{3}{|c|}{15} \\
\hline Variable Area & DK1 & DK2 & $\mathrm{DE}$ & DK1 & DK2 & $\mathrm{DE}$ & DK1 & DK2 & $\mathrm{DE}$ \\
\hline$\Delta$ solar $_{d}$ & & & 0.01 & & & 0.01 & & & 0.01 \\
\hline$\Delta \operatorname{solar}_{d}^{p}$ & & & 0.01 & & & 0.01 & & & 0.01 \\
\hline$\Delta$ solar_pen $_{d}$ & & & 0.01 & & & 0.01 & & & 0.01 \\
\hline$\Delta s o l a r \_p e n_{d}^{p}$ & & & 0.01 & & & 0.01 & & & 0.01 \\
\hline$\Delta g_{a} s_{d}$ & 0.01 & 0.01 & 0.01 & 0.01 & 0.01 & 0.01 & 0.01 & 0.01 & 0.01 \\
\hline$\Delta w_{i n d}$ & & & 0.01 & & & 0.04 & & & 0.67 \\
\hline$\Delta$ wind_pen $_{w}$ & & & 0.01 & & & 0.01 & & & 0.60 \\
\hline$\Delta \operatorname{solar}_{w}$ & & & 0.17 & & & 0.16 & & & 0.22 \\
\hline$\Delta$ solar_pen $w$ & & & 0.13 & & & 0.23 & & & 0.19 \\
\hline$\Delta v r e_{w}^{s t d}$ & & & 0.01 & & & 0.01 & & & 0.42 \\
\hline$\Delta \operatorname{exim}_{w}$ & 0.01 & 0.01 & & 0.01 & 0.01 & & 0.05 & 0.01 & \\
\hline$\Delta g a s_{w}$ & 0.01 & 0.01 & 0.01 & 0.01 & 0.01 & 0.11 & 0.01 & 0.01 & 0.20 \\
\hline
\end{tabular}

Table 12: Augmented Dickey-Fuller test p-values for differenced time series. All figures have been rounded to two decimal places. Empty cells indicate that the variable is not used for all areas. 


\section{Appendix B Model Selection}

\begin{tabular}{|c|c|c|c|c|c|c|}
\hline & DK1 & & DK2 & & $\mathrm{DE}$ & \\
\hline Model Test & AIC & L-B & AIC & L-B & AIC & $\mathrm{L}-$ \\
\hline SARMA $(1,0)(1,0)[7]$ & 3115.82 & 3 & 3403.95 & 3 & 84.30 & 3 \\
\hline $\operatorname{SARMA}(1,1)(1,0)[7]$ & 3102.47 & 3 & 3388.85 & 3 & 676.24 & 6 \\
\hline SAF & 3022.43 & 3 & 3293.06 & 3 & 549.72 & 3 \\
\hline $\mathrm{SAF}$ & 2963.46 & 3 & 3245.79 & 3 & 513.45 & 3 \\
\hline $\operatorname{SARMA}(1,2)$ & 2913.48 & 26 & 3196.09 & 7 & 503.46 & 30 \\
\hline $\operatorname{SARMA}(1,2)(2,1)[7]$ & & & 3181.10 & 30 & 491.84 & 30 \\
\hline $\operatorname{SARMA}(1,2)(1,2)[7]$ & 2908.93 & 30 & & & & \\
\hline $\operatorname{SARMA}(2,1)(2,1)[7]$ & 2908.53 & 30 & 3180.41 & 30 & 490.67 & 30 \\
\hline
\end{tabular}

Table 13: Statistically significant and AIC-improving iteration steps of the daily model for DK1, DK2, and DE.

\begin{tabular}{|c|c|c|c|c|c|c|}
\hline & DK1 & & DK2 & & $\mathrm{DE}$ & \\
\hline$\overbrace{\text { Model }}$ Test & AIC & L-B & AIC & L-B & AIC & L-B \\
\hline SARMA $(1,0)(1,0)[7]$ & -319.2 & 4 & -467.38 & 3 & 142.30 & 7 \\
\hline $\operatorname{SARMA}(1,1)(1,0)[7]$ & -332.18 & 3 & -476.81 & 3 & 138.09 & 7 \\
\hline $\operatorname{SARMA}(1,0)(1,1)[7]$ & -541.08 & 4 & -660.86 & 3 & 37.90 & 2 \\
\hline $\operatorname{SARMA}(1,1)(1,1)[7]$ & -556.9 & 3 & -675.71 & 3 & 24.25 & 30 \\
\hline $\operatorname{SARMA}(1,2)(1,1)[7]$ & -584.9 & 4 & -738.37 & 6 & & \\
\hline $\operatorname{SARMA}(1,1)(2,1)[7]$ & & & & & 20.65 & 30 \\
\hline $\operatorname{SARMA}(1,1)(1,2)[7]$ & & & & & 19.30 & 30 \\
\hline $\operatorname{SARMA}(1,2)(2,1)[7]$ & -586.7 & 4 & -746.59 & 6 & & \\
\hline $\mathrm{A}(2,1)(1,1)[7]$ & -586.38 & 4 & & & & \\
\hline $\operatorname{SARMA}(1,2)(1,2)[7]$ & -586.9 & 4 & -747.18 & 6 & & \\
\hline $\operatorname{SARMA}(2,1)(2,1)[7]$ & -588.5 & 4 & & & & \\
\hline
\end{tabular}

Table 14: Statistically significant and AIC-improving iteration steps of the intraday model for DK1, DK2, and DE. The reported figures are for peak hours. 


\begin{tabular}{l|ccccccc}
\hline \multicolumn{1}{c|}{ Test } & DK1 & & DK2 & \multicolumn{4}{c}{ DE } \\
\hline Model & AIC & L-B & AIC & L-B & AIC & L-B \\
\hline AR(1) & 441.11 & 4 & 502.10 & 6 & 172.94 & 30 \\
$\operatorname{MA}(1)$ & 447.06 & 2 & 504.61 & 4 & 173.91 & 30 \\
SARMA $(1,0)(1,0)[4]$ & 432.23 & 30 & 498.08 & 30 & & \\
SARMA $(1,0)(0,1)[4]$ & 431.86 & 30 & 497.32 & 30 & &
\end{tabular}

Table 15: Statistically significant and AIC-improving iteration steps of the weekly model for DK1, DK2, and DE. 


\section{Appendix C Alternative Specifications}

\begin{tabular}{|c|c|c|c|c|}
\hline $\begin{array}{c}\text { Variable } \\
\text { Area }\end{array}$ & DK1 & DK2 & $\mathrm{DE}$ & $\mathrm{DE}$ \\
\hline wind $_{d}$ & $\begin{array}{l}-0.0897^{a} \\
(0.0158)\end{array}$ & $\begin{array}{l}-0.0687 \\
(0.0146)\end{array}$ & $\begin{array}{l}0.0329^{a} \\
(0.0145)\end{array}$ & \\
\hline$\Delta$ solar $_{d}$ & & & & $\begin{array}{r}-0.0360^{b} \\
(0.0191)\end{array}$ \\
\hline$\alpha_{0}$ & 2.4019 & 2.2073 & 1.9365 & 2.2393 \\
\hline$\alpha_{1}$ & 0.9494 & 0.9301 & 0.9861 & 0.9864 \\
\hline$\alpha_{7}$ & 0.9982 & 0.9994 & 0.9996 & 0.9998 \\
\hline$\beta_{1}$ & -0.5889 & -0.5371 & -0.7538 & -0.7409 \\
\hline$\beta_{2}$ & -0.1881 & -0.1732 & -0.1389 & -0.1470 \\
\hline$\beta_{7}$ & -0.9180 & -0.8885 & -0.8233 & -0.8306 \\
\hline$\beta_{14}$ & $-0.0599^{a}$ & -0.0964 & -0.1614 & -0.1592 \\
\hline AIC & 2879.03 & 3161.19 & 489.95 & 491.03 \\
\hline L-B & 30 & 30 & 30 & 30 \\
\hline & vel & & & \\
\hline
\end{tabular}

Table 16: An alternative specification for the daily volatility model. All coefficients are statistically significant at the $1 \%$ level unless otherwise noted.

\begin{tabular}{|c|c|c|c|c|c|c|c|c|c|c|c|}
\hline Area & DK1 & DK2 & $\mathrm{DE}$ & DK1 & DK2 & $\mathrm{DE}$ & $\mathrm{DE}$ & $\mathrm{DE}$ & DK1 & DK2 & $\mathrm{DE}$ \\
\hline $\begin{array}{ll}\text { Variable } & \text { Block } \\
\end{array}$ & Off-peak 1 & Off-peak 1 & Off-peak 1 & Peak & Peak & Peak & Peak & Peak & Off-peak 2 & Off-peak 2 & Off-peak 2 \\
\hline wind $_{d}$ & $\begin{array}{l}-0.1524 \\
(0.0076)\end{array}$ & $\begin{array}{l}-0.0937 \\
(0.0060)\end{array}$ & $\begin{array}{l}-0.2854 \\
(0.0153)\end{array}$ & $\begin{array}{l}-0.1065 \\
(0.0045)\end{array}$ & $\begin{array}{l}-0.0659 \\
(0.0038)\end{array}$ & $\begin{array}{l}-0.1488 \\
(0.0089)\end{array}$ & & & $\begin{array}{l}-0.0943 \\
(0.0043)\end{array}$ & $\begin{array}{l}-0.0623 \\
(0.0040)\end{array}$ & $\begin{array}{l}-0.1888 \\
(0.0080)\end{array}$ \\
\hline$\Delta \operatorname{solar}_{d}$ & & & & & & & $\begin{array}{l}-0.0508 \\
(0.0139)\end{array}$ & & & & \\
\hline$v e_{d}$ & & & & & & & & $\begin{array}{l}-0.1710 \\
(0.0132)\end{array}$ & & & \\
\hline$\alpha_{0}$ & 4.3733 & 3.9516 & 5.7170 & 4.4112 & 4.1188 & 4.9638 & 3.7154 & 3.7189 & 4.2444 & 3.9636 & 5.2483 \\
\hline$\alpha_{1}$ & 1.1257 & 0.9235 & 0.6688 & 1.1390 & 0.9137 & 0.7256 & 0.6432 & 0.6139 & 1.0447 & 0.9543 & 0.7929 \\
\hline$\alpha_{2}$ & -0.1862 & & & -0.2116 & & & & & -0.0882 & & \\
\hline$\alpha_{7}$ & 0.9870 & 0.9296 & 0.9272 & 0.9968 & 0.9687 & 0.9380 & 0.9376 & 0.9350 & 0.9260 & 0.9616 & 0.9491 \\
\hline$\alpha_{14}$ & $-0.0289^{a}$ & & & $-0.0310^{a}$ & & & & & $0.0360^{a}$ & & \\
\hline$\beta_{1}$ & -0.7736 & -0.4865 & -0.3413 & -0.7504 & -0.4264 & -0.4346 & -0.2939 & -0.2061 & -0.7118 & -0.6085 & -0.4830 \\
\hline$\beta_{2}$ & & -0.1627 & & & -0.1943 & & & & & -0.0806 & \\
\hline$\beta_{7}$ & -0.8863 & -0.7768 & -0.6929 & -0.8144 & -0.7371 & -0.5425 & -0.5462 & -0.5111 & -0.9122 & -0.9226 & -0.8095 \\
\hline$\beta_{14}$ & & $-0.0450^{a}$ & $-0.0459^{a}$ & & -0.0744 & $-0.0464^{a}$ & -0.0892 & -0.0967 & & $0.0112^{a}$ & $0.0210^{a}$ \\
\hline $\mathrm{AIC}$ & 854.01 & 635.59 & 605.94 & -1065.55 & -1021.47 & -217.34 & -8.81 & -145.37 & -1239.92 & -828.71 & -775.89 \\
\hline L-B & 30 & 30 & 4 & 4 & 6 & 30 & 30 & 30 & 4 & 5 & 8 \\
\hline
\end{tabular}

${ }^{a}$ not significant

Table 17: Alternative specifications for the intraday model. All coefficients are statistically significant at the $1 \%$ level unless otherwise noted. 


\begin{tabular}{|c|c|c|c|c|c|}
\hline $\begin{array}{c}\text { Area } \\
\text { Variable }\end{array}$ & DK1 & DK2 & $\mathrm{DE}$ & $\mathrm{DE}$ & $\mathrm{DE}$ \\
\hline $\operatorname{wind}_{w}$ & $\begin{array}{c}0.2070 \\
(0.0723)\end{array}$ & $\begin{array}{l}0.1010^{c} \\
(0.0734)\end{array}$ & & & \\
\hline$\Delta w_{i n d} w$ & & & $\begin{array}{l}0.1370^{a} \\
(0.0578)\end{array}$ & & \\
\hline$\Delta$ solar $_{w}$ & & & & $\begin{array}{l}-0.1901^{c} \\
(0.1163)\end{array}$ & \\
\hline$v r e_{w}$ & & & & & $\begin{array}{l}0.2013^{b} \\
(0.1159)\end{array}$ \\
\hline$\alpha_{0}$ & $0.2357^{c}$ & 1.1097 & 1.9681 & 1.9698 & $0.1351^{c}$ \\
\hline$\alpha_{1}$ & 0.5996 & 0.6309 & 0.8790 & 0.8413 & 0.9035 \\
\hline$\beta_{1}$ & $-0.3404^{c}$ & $-0.3295^{c}$ & -0.7690 & $-0.7099^{a}$ & -0.8048 \\
\hline$\overline{\mathrm{AIC}}$ & 435.11 & 503.62 & 168.83 & 171.76 & 171.99 \\
\hline L-B & 11 & 5 & 30 & 30 & 30 \\
\hline
\end{tabular}

Table 18: An alternative specification for the weekly volatility model. All coefficients are statistically significant at the $1 \%$ level unless otherwise noted. 